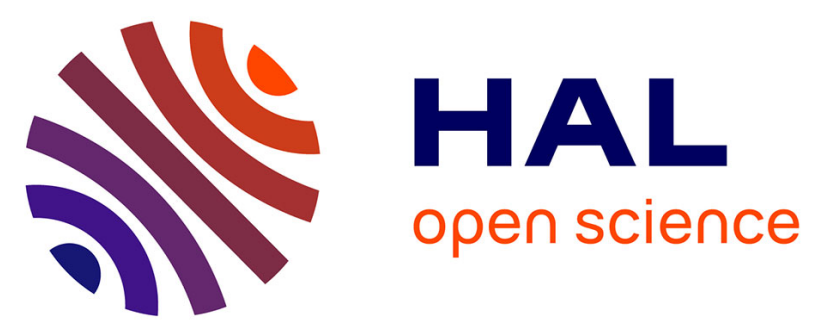

\title{
Chemical highlight supporting the Lipid A role in efficient biological adaptation of Gram-negative bacteria face to external stresses
}

Azza Troudi, Jean Marie Pagès, Jean Michel Brunel

\section{- To cite this version:}

Azza Troudi, Jean Marie Pagès, Jean Michel Brunel. Chemical highlight supporting the Lipid A role in efficient biological adaptation of Gram-negative bacteria face to external stresses. Journal of Medicinal Chemistry, 2021, 64 (4), pp.1816-1834. 10.1021/acs.jmedchem.0c02185 . hal-03368186

\section{HAL Id: hal-03368186 \\ https://hal.science/hal-03368186}

Submitted on 6 Oct 2021

HAL is a multi-disciplinary open access archive for the deposit and dissemination of scientific research documents, whether they are published or not. The documents may come from teaching and research institutions in France or abroad, or from public or private research centers.
L'archive ouverte pluridisciplinaire HAL, est destinée au dépôt et à la diffusion de documents scientifiques de niveau recherche, publiés ou non, émanant des établissements d'enseignement et de recherche français ou étrangers, des laboratoires publics ou privés. 


\title{
Chemical highlight supporting the Lipid A role in efficient biological adaptation of Gram-negative bacteria face to external stresses
}

\author{
Azza Troudi $^{1,2}$, Jean Marie Pagès $^{1}$ and Jean Michel Brunel ${ }^{1 *}$ \\ ${ }^{1}$ UMR_MD1, U-1261, Aix Marseille Univ, INSERM, SSA, MCT, 13385 Marseille, France. \\ E-mail: bruneljm@yahoo.fr \\ ${ }^{2}$ Laboratory of Microorganisms and Active Biomolecules, Department of Biology, Faculty of \\ Sciences of Tunis, University of Tunis El Manar, Tunis 1008, Tunisia
}

\begin{abstract}
The outer membrane $(\mathrm{OM})$ of Gram-negative bacteria provides an efficient barrier against external noxious compounds such as antimicrobial agents. Associated with drug target modification it contributes to the overall failure of chemotherapy. In the complex OM architecture, Lipid A plays an essential role by anchoring the lipopolysaccharide in the membrane and ensuring the spatial organization between lipids, proteins, and sugars. Currently, the targets of almost all antibiotics are intracellularly located and required for translocation across membranes. We report herein an integrated view of Lipid A synthesis, membrane assembly, a structure comparison at the molecular structure level of numerous Gram-negative bacterial species as well as its recent use as a target for original antibacterial molecules. This review paves the way for a new vision of a key membrane component that acts during bacterial adaptation to environmental stresses and for the development of new weapons against microbial resistance to usual antibiotics.
\end{abstract}

\section{Introduction}

The Gram-negative bacteria envelope comprises an outer membrane (OM) exhibiting an original architecture with an asymmetrical location of lipopolysaccharide (LPS) when usual 
phospholipids organize the inner layer, and an inner/cytoplasmic membrane (IM) which contains phospholipids, sensors, transporters, enzymes, and the respiration/energy system (Figure 1A). ${ }^{1-2}$ A documented paper by Simpson \& Trent presented the LPS in the OM properties including biological activities during infection, interactions with the immune system, pathogenesis, and $\mathrm{OM}$ vesicles, as well as protection against antimicrobial compounds. $^{3}$

Thus, the structure of the lipid bilayer and protein organization as well as the sophisticated composition of the OM govern the permeability properties of the latter and consequently the susceptibility of the microorganism to antimicrobial agents targeting intracellular processes. ${ }^{4}$ Currently, the increase and spread of antibiotic resistant bacterial strains is a worrying health concern. Importantly, the alteration of envelope permeability is reported in a majority of MDR isolates. Several alterations, termed membrane-associated mechanisms of resistance ${ }^{5}$, exhibit changes in the lipid or protein composition of the OM. This phenomenon requires an analysis of the modification to understand its involvement in the antibiotic susceptibility of a bacterium to a given antibiotic. Considering the literature focused on Lipid A, the aim of this review is to enlighten the role of this important component of OM in bacterial adaptation and physiology. In addition, Lipid A is discussed with regards to the development of molecules that specifically target this key component to generate original antibiotic candidates that are susceptible to combatting multiresistant Gram-negative bacteria.

Thus, this review focuses exclusively on Lipid A in Gram-negative bacteria and its pivotal role in adaptation to environmental changes, and it does not cover the other already wellreviewed role of O-antigen variation in biological activities and the immune response. ${ }^{6-8}$

\section{OM, structure, and components}

The marked difference between Gram-negative and Gram-positive bacteria is due to the OM and to the lipopolysaccharide (LPS) located in this outer leaflet whereas the phospholipids 
(composed of approximately phosphatidylglycerol 15\%, phosphatidylethanolamine $80 \%$ and cardiolipin 5\%) are confined to the inner leaflet of this OM (Figure 1A). ${ }^{4,9}$ This membrane must adapt its composition to the variations in the external environment, and the associated functions implicate the presence of complex regulation systems. Consequently, the outer membrane is a lipid bilayer membrane that contains numerous proteins possessing important functions. ${ }^{10}$ Among them, lipoproteins provide stability to the membrane by bridging OM to peptidoglycan, and $\beta$-barrel proteins serve essential functions in the transport/influx of solutes and receptor-signaling. In addition, membrane biogenesis represents the two main classes of proteins in the OM. Another type of protein possessing structural and enzymatic functions or implicated in plasmid conjugation can also be found (Figure 1B). ${ }^{11-12}$ The bacteria also possesses elements such as the flagellum, representing a supramolecular motility machine ${ }^{13}$, the pili, which are involved in surface adherence and motility ${ }^{14}$ and a large number of protein receptors that are used by phages, bacteriocins, and drugs present in the surrounding medium. ${ }^{15}$

Thus, this unique OM controls the exchange process between the bacterial cell and its environment through porins (Omps) possessing specific size-exclusion properties and LPS acting as a selective barrier both of which are involved in the diffusion of nutrients, dissemination of wastes and transport of other molecules such as iron or even more hydrophobic compounds. ${ }^{2}$ Otherwise, OM retains vital components for cell livelihood such as amino acids, sugars, vitamins, and ions, as well as degradative and detoxifying enzymes in the periplasmic space. ${ }^{16-17}$ In this context, Gram-negative bacteria use different mechanisms of antibiotic resistance ${ }^{18-20}$ one of which is based on a decrease in OM permeability which blocks drug penetration and limits its accumulation in association with efflux pumps. ${ }^{2,5,21}$ The antibiotic structure and target modifications modulate the affinity of the drug and the OM barrier with efflux pumps limit the antibiotics internal concentration. Consequently, they contribute together to the overall failure of antibiotic therapy. ${ }^{22-23}$ Recently, Vergalli et al 
showed that the balance between antibiotic influx/efflux is a prominent parameter that controls the translocation across bacterial membrane and governs the antibiotic concentration in the bacterial cell. ${ }^{24-25}$ The OM permeability plays a major role in the susceptibility of Gram-negative bacteria to antibiotics and this behavior could be manipulated by modifications in proteins or the lipid composition of the OM which can significantly lead to resistance or antibiotic susceptibility in several species. ${ }^{2,21}$

Figure 1. Schematic illustration of the Gram-negative bacteria envelope

The lipopolysaccharide (LPS) includes a poly- or oligosaccharide responsible for a range of three biologically and chemically distinct domains (Figure 1B, 1C). ${ }^{26-27}$ The structure of LPS consists of an O-antigen chain, a core oligosaccharide, and a lipid component named Lipid A as described below. ${ }^{28}$

\section{a. O-antigen or $\mathrm{O}$-specific polysaccharide}

Complete LPS, which comprises three regions the Lipid A, the core and the O-antigen is called smooth $(S)$-form-LPS while LPS lacking the O-antigen is named rough $(R)$-form LPS or lipooligosaccharide (LOS). ${ }^{26,}{ }^{29}$ The O-antigen can only be found in smooth-type LPS, where it determines the antigenic properties (Figure 1C) and consists of repeating units of usually not more than five sugar units possessing a hydrophilic character. Present in the LPS structure, the O-antigen leads to a serotype specificity in the bacterial strains that allows it to escape the host defense system, particularly the attack of serum complement. ${ }^{30}$

\section{b. Oligosaccharide core KDO region}

The core region (Figure 1C) represents the link between Lipid A and O-antigen and contains a hydrophobic inner core and a hydrophilic outer core. It consists of 15 sugar residues and confers antigenic properties in the case of a missing O-antigen or "rough" type LPS. ${ }^{31}$ The LPS core starts with at least one residue of 3-deoxy-d-manno-oct-ulosonic acid (Kdo), which is directly linked to one of the sugar moieties of Lipid A (Figure 1B).

\section{c. Lipid A}


Lipid A is the proximal portion of LPS and presents a hydrophobic character. It is anchored in the bacterial OM with variable composition of the acyl residues and phosphoryl groups. Lipid A is involved in the endotoxin activities of Gram-negative bacteria and is possibly associated with outer membrane proteins in the recognition binding sites for bacteriocins, and phages, and it also participates in the binding steps on cells. ${ }^{26,32}$

Figure 2 summarizes the different biological activities of LPS and Lipid A, which are not always damaging and can sometimes be beneficial for the host. ${ }^{33}$

Figure 2. Chemical structure and some biological properties of E. coli Lipid A In addition, Lipid A presents a close contact with some porins leading to a lipid/ protein complex possessing a hexagonal network structure. Lipid A therefore can play a vital role in the maintenance of the integrity of the outer membrane and cell shape. ${ }^{32,34}$

\section{Structure and biosynthesis of Lipid A}

\section{a. Lipid A structure}

To elucidate the Lipid A structure, Luderitz and Westphal subjected lipopolysaccharide to an acidic treatment disrupting the Lipid A core covalent link and obtained the first fragment of LPS containing a deletion of the polysaccharide chains of O-antigen or the nucleus. Later, this fragment was called Lipid A and shown to be involved in the endotoxin activity of the bacterium. In 1984, the first synthetic Lipid A molecule was obtained exhibiting similar biological and toxic characteristics to native E. coli Lipid A. ${ }^{35-37}$ From a structural perspective, Lipid A represents the anchor moiety of LPS in the OM, and its distinctive phosphoglycolipid structure is highly preserved among Gram-negative bacteria. Basically, the Lipid A structure consists of a 1,4 -bisphosphorylated- $\beta$-D-glucosaminyl-( $1 \rightarrow 6)$-Dglucosamine disaccharide backbone with four to seven fatty acid chains attached to the Nacetylglucosamine sugars. ${ }^{38-39}$ Most Gram-negative bacterial strains present some variations in Lipid A structure corresponding to the aliphatic chains' length and number, nature and 
location of acyl groups, types of hexosamines present, degree of phosphorylation as well as presence of substituents, such as pEtN and 4-amino-4-deoxy-1-arabinose (1-Ara4N). Lipid A can also be chemically modified by phosphoethanolamine, aminoarabinose, or glycine residues, which are key for bacterial pathogenesis/virulence. ${ }^{40}$

In E. coli, Lipid A is extensively documented and can include more than $10^{6}$ Lipid A residues and almost $10^{7}$ glycerophospholipids ${ }^{41}$ allowing the determination of the presence of six fatty acids: four hydroxylated fatty acids having a sequence length of 14 carbons and two $(R)-3-$ hydroxy fatty acids. The GlcN residues of the decreasing facet (GlcN I) are acylated by no hydroxy fatty acids (12: 0 and 14: 0). It is noteworthy that few molecular species including a further fatty acid connected to the 3-hydroxy acid linked to an amide and a phosphate moiety substituted through ethanolamine phosphate (from GlcN I) were reported. ${ }^{42}$

In E. coli and Salmonella spp, the glucosamines are acylated at positions 2, 3, and 3' and phosphorylated at positions 1 and 4 '. Thus, the distal glucosamine, usually present two additional secondary acyl chains and the mature Lipid A is mainly hexa-acylated.

The general structure of the core region is constituted by a nonrepeated oligosaccharide which is bonded to a Lipid A glycosamide, made up of 3-deoxy-D-manno-octo-2-ulosonic acid named Kdo residues, or heptoses and hexoses. It is noteworthy that Kdo can be substituted by phosphate or phosphoethanolamine. ${ }^{43}$

\section{b. Lipid A biosynthesis}

The first identification of Lipid A demonstrated that this component could be released from the rest of the LPS molecules by mild-acid hydrolysis conditions. The genetic, molecular and enzymatic study of Lipid A biosynthesis has been extensively performed for E. coli and Salmonella and is referred to as the Raetz pathway because a large part of the research was reported by Raetz et al. (Figure 3). ${ }^{41}$

Figure 3. The Raetz pathway of E. coli Lipid A biosynthesis 
The biosynthesis of $E$. coli Lipid A requires nine enzymes for catalysis (LpxA, LpxC, LpxD, LpxH, LpxB, LpxK, KdtA, LpxL, LpxM) and three protein-bound acyl donor substrates along with UDP-N-acetylglucosamines (UDP-GlcNAc), ATP, and CMP-3-deoxy-D-mannooctulosonic acid (CMP-Kdo). The different enzymes involved in Lipid A biogenesis are either expressed in the cytoplasm or anchored to the IM to achieve the final assembly of LPS in the OM. Conversely, the cytosolic proteins LpxA, LpxC and LpxD catalyze multiple reactions converting UDP-GlcNAc into UDP-2,3-diacyl-glucosamine. ${ }^{38,41,44-46}$

Lipid A synthesis is initiated in the cytoplasm by the acylation of $\mathrm{N}$-acetyl glucosamine linked to a sugar moiety (UDP-GlcNAc) and recruitment of LpxA enzyme to afford UDP-3O-(acyl)-GlcNAc. This enzyme grafts the acyl chain from $R$ - $\beta$-hydroxymyristoyl-ACP to the 3-OH group of UDP-GlcNAc through catalysis of a thermodynamically unfavorable reaction. ${ }^{34,} 41$ To drive the reaction forward, $\mathrm{LpxC}$, a $\mathrm{Zn}^{2+}$-dependent metalloenzyme, hydrolyzes the 2-acetamido functionality, and thus catalyzes the first committed step. Following de-acetylation, another $R$ - $\beta$-hydroxymyristoyl moiety is then incorporated by LpxD to generate the 2-amino group, yielding UDP-2,3-diacyl-glucosamine. After the second acylation by LpxD, UDP-2,3-diacylglucosamine is cleaved at its pyrophosphate bond by the specific pyrophosphatase LpxH, which removes the sugar nucleotide carrier from UDP-2,3diacylglucosamine to generate 2,3-diacylglucosamine-1-phosphate, known as Lipid X. ${ }^{38,41,44-}$ 46

The resulting product is a tetra-acylated glucosamine disaccharide, which is inserted in the inner leaflet of the IM and is sometimes termed the "Lipid A disaccharide". Following this condensation step, a specific kinase, LpxK, phosphorylates the $4^{\prime}$ position of the disaccharide to form the biphosphorylated Lipid IVA which exhibits some of the properties of endotoxins in mouse cells as potent endotoxin-like agonist whereas it is an endotoxin antagonist in human cells. This unusual pharmacology of Lipid IVA is determined by whether the target cells express mouse or human TLR4. 
Prior to late-stage acylation, the addition of two 2-keto-3-deoxyoctonate (Kdo) sugar groups of the core oligosaccharide to Lipid IVA sugar is required. This step is mediated by a bifunctional enzyme KdtA that catalyzes two successive glycosyl transfer reactions to form

Kdo2-Lipid IVA. ${ }^{38,41,44-46}$ Finally, two additional acylations catalyzed by LpxL and LpxM acyltransferases occur and LpxL adds lauroyl and myristoyl secondary acyl chains, respectively, to yield hexa-acylated Lipid A. The final compound is enzymatically flipped and oriented towards the periplasm via the addition of O-antigenic polysaccharide, and it is subsequently transported to the OM..$^{38,41,44-46}$

As we previously mentioned, Lipid A is an essential component for Gram-negative bacteria toxicity. The characterizations of its key differences provide a reminder of the fundamental aims for understanding their biological role. Figure 4 summarizes the most common structures of Gram-negative bacterial Lipid A reported in the literature.

Figure 4. Most common structures of Gram-negative bacterial Lipid A

Thus, the chemical structure of Lipid A greatly varies from one Gram-negative bacterial strain to another. However, many similarities can be observed at the backbone level, as well as low structure variability. Generally, the well-conserved structure is formed by a bisphosphorylated $\beta, 1 \rightarrow 6$-linked disaccharide of D-glucosamine ( $\mathrm{GlcN}$ and GlcN3N), basically consisting of four residues of $R-3$ hydroxyl groups with, ester and amide functions. This backbone also carries a large panel of fatty acids chain length that depends on the nature of the bacterial species (see supplementary data).

\section{LPS and antibiotic resistance}

Infectious diseases are a major human health threat: from the discovery of penicillin and other antibiotics, the resistance of Gram-negative bacteria has recently emerged as a serious global health problem (https://www.who.int/news-room/fact-sheets/detail/antibiotic-resistance). Worrisome bacteria such as Enterobacteriaceae, $P$. aeruginosa, and A. baumannii use diverse 
mechanisms of resistance, including antibiotic degradation, target modification, permeability modulation and efflux associated or not with the acquisition of genetic mobile elements that increases the resistance intensity. Interestingly, Gram-negative bacteria are resistant to many antibiotics that are effective against Gram-positive organisms due to the intrinsic nonsusceptibility associated with the OM permeability barrier and the lack of drug accumulation close to its target. ${ }^{5,18,24,47}$. Numerous works have examined the mechanisms of resistance of Gram-negative bacteria. Nevertheless, the close relationships between the Lipid A structure and antibiotic bacterial resistance remain poorly understood. ${ }^{18-20}$

Some of antibiotics reach the cytoplasm by permeating the OM such as macrolides (erythromycin), fusidic acid, aminoglycosides (kanamycin gentamycin) and cationic peptides. Other hydrophobic drugs like tetracycline and quinolones use two different pathways for penetration: the lipid- and porin-mediated pathway in the case of small hydrophilic compounds. $^{2,4,48-51}$

Regarding polymyxin that targets $\mathrm{OM}$, some studies have demonstrated that polymyxinresistant $S$. Typhimurium mutants bind only $25 \%$ of the amount of polymyxin bound by susceptible strains and tolerate up to 100 times higher concentrations of polymyxin B. It has been reported that LPSs isolated from mutants also show less binding of polymyxin $\mathrm{B}$, and an analysis of their respective LPSs demonstrated that they contained 4 to 6 times more 4aminoarabinose and phosphoethanolamine (PEtN). These modifications, due to the esterification of Lipid A phosphates by these moieties, strongly decrease the negative total charge of the LPS molecule (e.g. from 1.5 to minus 1 for L-Ara4N or from minus 1.5 to 0 for PEtN) that reduce the electrostatic repulsion between adjacent LPS molecules. ${ }^{4}$, 52 The resulting more closely packed LPS layer confer a reduced susceptibility of the mutants not only to polymyxin B but also to PMBN, EDTA and other cationic agents by reducing the affinity for these compounds. ${ }^{48,52-55}$ 
In the same context, studies of $K$. pneumoniae polymyxin resistant strains have reported that the phosphate groups of Lipid A contain five times more L-Ara4N than the susceptible strain. This decrease of the negative charge of $\mathrm{OM}$ reduces the interaction with polymyxins, consequently leading to increased resistance. ${ }^{56}$ Han et al demonstrated for the first time, that polymyxin-resistant strains of $P$. aeruginosa use deacylation and not the phosphate Lipid A modification to confer high-level polymyxin resistance. Lipid A deacylation is performed by removal of the fatty acyl chain at position 3 which induces a decrease in the hydrophobic interactions with polymyxins. This represents a kind of 'innate immunity' response to polymyxins by a compensatory mechanism to the amino-arabinose modification for polymyxin-resistant strains. ${ }^{57}$

Moreover, it has been reported that strains containing a full-length LPS have an intrinsic resistance to hydrophobic antibiotic classes such as macrolides and aminoglycosides. ${ }^{52,55,58-62}$ It is also well-known that six fatty acid tails in Lipid A confer a low OM permeability against hydrophobic drugs. About the relationship between permeability and some defective Lipid A resistant and mutant strains isolated from E. coli, the Lipid A hexa-acylated type is not essential for the normal function of the OM barrier and that the last two fatty acids transfer to the nascent Lipid A are not a prerequisite step. ${ }^{63}$

Interestingly, E. coli $m s b B$ mutant strains with defective penta-acylated Lipid A containing only three fatty acids linked to $\mathrm{GlcN}^{\prime}$ presented the same permeability barrier against both hydrophobic antibiotics and large glycopeptides drugs as the parent-type control strain. The $m s b B$ penta-acylated form devoid of the myristic acid residue of nonreducing glucosamine can functionally replace the hexa-acylated form and preserve the OM barrier that protect against various hydrophobic antibiotics, e.g. rifampin, fusidic acid, erythromycin, clindamycin and azithromycin. ${ }^{63}$

As previously discussed, the modification or removal of the phosphate groups on Lipid A is one of the mechanisms of resistance against cationic antimicrobial peptides (CAMPs). Powers 
and Trent observed that while LPS or LOS-deficient, A. baumannii strains are highly resistant to polymyxin; otherwise, they become more permeable and sensitive to other antibiotic classes that are normally ineffective against Gram-negative bacteria. ${ }^{64}$ A. baumannii colistin resistant strains show another kind of modifications. They typically use PEtN phosphorylation exactly at the 4'-phosphate or 1-phosphate group of Lipid A but they can also use Lipid A glycosylation with galactosamine (hexosamine) at the 1-phosphate group. This unique modification is similar to the L-Ara4N modification in colistin (Polymyxin E)-resistant enteric bacteria. $^{56}$

PEtN modification is mediated by EptA enzyme that ensures the transport of PEtN from phosphatidylethanolamine to Lipid A mainly to the 1-phosphate group but also to the 4'phosphate. ArnT is the enzyme responsible for the branching of L-Ara4N to Lipid A at the phosphate at position 4', as well as the 1-phosphate position. ${ }^{43}$ In the absence of L LAra4N or under other growth conditions, EptA can also modify the Lipid A at the 4' position with a second phosphoethanolamine moiety. ${ }^{34}$

Some Enterobacteriaceae such as Salmonella and Escherichia use a similar Lipid A modification to confer resistance, with other species involving various alternatives such as $V$. cholerae that can modify the acyl chains of its Lipid A by adding amino acid moieties, or Bordetella isolates that switch the phosphates of their Lipid A with glucosamine. These two variations greatly increase CAMP resistance in these strains compared with their sensitive parental ones. ${ }^{43}$ Altogether, these data suggest that the presence of 4-amino-4-deoxy-Larabinose in LPS is the key to resistance against peptides. This is the case for Burkholderia cenocepacia displaying an original resistance to antimicrobial peptides and other antibiotics thanks to this component. The defective synthesis of 4-amino-4-deoxy-L-arabinose observed in mutants of $B$. cenocepacia strains highly increases susceptibility to polymyxin and melittin and alters OM permeability. The authors suggested that LPS modification that takes place 
after the binding of 4-amino-4-deoxy-L-arabinose molecule to Lipid A determines the LPS transport and its correct assembly into the OM. ${ }^{65}$

In the last decade, studies have shown that the alteration of LPS transport is deleterious for most Gram-negative bacteria. ${ }^{20,66-67}$ The LPS transport from the E. coli inner to the outer membrane is managed by seven essential proteins named Lpt (LptA, B, C, D, E, F and G). Unfortunately, this mechanism of transport remains poorly molecularly defined despite reports that functional Lpt proteins play key roles in OM assembly and bacterial survival. ${ }^{68-70}$ Divalent cations also play an important role in the branching of Lipid A headgroups, and dynamic simulations and NMR studies have indicated that the tight cross-linking of LPS headgroups promotes a slow diffusion rate of LPS and consequently reduces OM permeability. ${ }^{71}$ Additionally, the disruption or damage of the OM structure could be obtained by removing $\mathrm{Mg}^{2+}$, which confers an easy route of entry for larger molecules across the membrane. $^{72}$

$\mathrm{OM}$ is characterized by a strong duality/antagonism between providing nutrient permeation needed by growing cells and maintaining a robust barrier against external aggression. ${ }^{2}$ The $\mathrm{OM}$ also constitutes a selective barrier via the presence of pore-forming proteins (Omp channel), since reaching the periplasm and cytoplasmic membrane constitute an important gateway for antibiotic efficiency. ${ }^{24,73}$ Any decrease in the penetration of these compounds can lead to resistance by altering their intrabacterial concentration. ${ }^{5}$ Several reports have related antibiotic resistance to the loss or functional change of porins in a large number of organisms, such as Escherichia, Enterobacter, Klebsiella, Neisseria, Pseudomonas. ${ }^{21,48,74}$ Studies have demonstrated that loss/reduction of the porin number, exchange of one porin for another and alteration of their function due to specific mutations increase the impermeability and contribute to antibiotic resistance. Interestingly, several strains express a high constitutive or inducible $\beta$-lactamase activity that amplifies the resistance profile in those porin minus strains. $^{4,21,24}$ 


\section{Perspective for combatting multidrug resistant Gram-negative bacteria: The lipid metabolism inhibitors}

Fatty acids are key components of biological membranes and are synthesized/modified through a repetitive cycle of four reactions involving condensation, reduction and dehydration of carbon-carbon bonds. ${ }^{75}$ Significant differences between bacterial and human fatty acid synthesis systems have been reported, including the typical organization and structure of enzymes involved as well as their specific locations and roles played by the fatty acids, making this system an attractive target for antibacterial drug discovery. ${ }^{76-79}$

In bacteria, during fatty acid biosynthesis, the chain elongation step consists of the condensation of acyl groups derived from acyl-ACP or acyl-CoA with malonyl-ACP involving condensing enzymes (FabH type) (Figure 5A). ${ }^{76,80}$ Thus, E. coli FabH selectively uses acetyl-CoA to initiate the pathway producing straight fatty acids chains. Interestingly, Bacillus subtilis contains two FabH isozymes (FabHA and FabHB) that are selective for

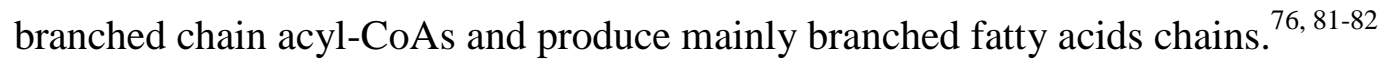

Figure 5. A) Bacterial fatty acid biosynthesis pathway. B) Structure and biological activities of known $\mathrm{FabF} / \mathrm{B}$, FabH inhibitors.

Different compounds having inhibitory effects on bacterial syntheses are described as antibiotics, such as cerulenin ${ }^{83}$, thiolactomycin ${ }^{84-87}$ platensimycin and platencin (Figure $\left.5 \mathrm{~B}\right){ }^{76 \text {, }}$ 80

Cerulenin was originally synthesized and isolated from a fungus Cephalosporium cerulean. ${ }^{88-}$

${ }^{89}$ Studies have demonstrated that this fungal toxin inhibits the eukaryotic and prokaryotic ketoacyl-acyl carrier protein synthases or condensing enzymes ${ }^{80}$ and presents a great selectivity for $\mathrm{FabB}^{82}$ in E. coli while FabF is less sensitive. ${ }^{75,90-92}$

Investigation of the cerulenin mode of action indicated that this antibiotic specifically blocks fatty acid and sterol biosynthesis in cell-free system. ${ }^{88}$ Most fatty acid synthesis inhibitors 
recurrently inhibit polyketide synthesis, and cerulenin appears to be a powerful inhibitor of this pathway. ${ }^{93}$ Thus, cerulenin inhibits fatty acid synthesis by forming a covalent bond with the catalytic cysteine located inside the active site and its tail plugs the long hydrophobic cavity that normally captures the growing acyl chain of the natural substrate. ${ }^{76,82,91,94}$ Alteration of lipid synthesis leads to the disruption of bacterial membrane with harmful consequences. ${ }^{95}$ Cerulenin inhibits FabF/B with an $\mathrm{IC}_{50}$ ranging from 0.1 to $2 \mu \mathrm{g} / \mathrm{mL}$ whereas the $\mathrm{IC}_{50}$ against $\mathrm{FabH}$ is $150 \mu \mathrm{g} / \mathrm{mL}^{82}$

Several natural $\beta$-ketoacyl-ACP synthases (KAS) inhibitors have been described such as thiolactomycin isolated in 1982 from a soil sample and obtained from fermentation broth of Nocardia species. ${ }^{81,87,96-97}$ This compound presented an original thiolactone structure that was chemically different from the usual antibiotics and was able to inhibit the incorporation of acetate into cellular fatty acids of E. coli. ${ }^{96}$ Thus, FabB was the main target of thiolactomycin that alters the activity of all three $\beta$-ketoacyl-ACP synthase condensing enzyme systems (I to III) and acetyl coenzyme A (CoA). ${ }^{75}$ Thiolactomycin inhibited KasA and KasB with $\mathrm{IC}_{50}$ values of $20 \mu \mathrm{M}$ and $90 \mu \mathrm{M}$ respectively and showed a moderate activity against a broad spectrum of both Gram-positive and negative bacteria, as well as mycobacteria. ${ }^{75,81,85,93,98-99}$ These preliminary data have stimulated studies to improve the antibacterial activity of this natural product and Merck has reported the isolation from S. platensis ${ }^{100-102}$ of a metabolite, namely, platensimycin possessing a dual mode of action similar to that of thiolactomycin but presenting 200-fold higher antibacterial activity against $S$. aureus than the latter. ${ }^{76}$ It has been recognized that this molecule exhibits a potent broad-spectrum activity against a wide range of Gram-positive bacteria such as methicillin-resistant S. aureus (MRSA) and vancomycin resistant enterococci (VRE) (Table S1). Furthermore, in vivo efficacy and low cytotoxicity have been reported in mice. ${ }^{100,}{ }^{103-104}$ Platensimycin is able to inhibit the elongationcondensing enzyme ketoacyl-acyl carrier protein synthase II (FabF) required for bacterial cell membranes building. ${ }^{93,103-105}$ More precisely, platensimycin has demonstrated a selective 
FabF inhibitory activity with $\mathrm{IC}_{50}$ value of $0.29 \mathrm{nM}$, respectively, whereas it presented a weak inhibition of $\mathrm{FabH}$ with an $\mathrm{IC}_{50}$ value of $247 \mu \mathrm{M} .^{76,93}$

Unfortunately, very weak antibacterial activity was noticed against Gram-negative pathogens, partially due to the efflux mechanisms as demonstrated by using a tolC mutant strain of $E$. coli exhibiting low susceptibility to platensimycin ${ }^{101,105}$ (Figure 5B). To conclude, platensimycin does not seem to be an attractive drug candidate due to its poor pharmacokinetic properties compromising its further clinical development. ${ }^{104}$

Platencin, a derivative of platensimycin antibiotic, was then isolated from a new strain of $S$. platensis MA733 collected from a soil sample from Spain $^{76}$ and reported to have strong antimicrobial activity against sensitive and resistant Gram-positive strains with MIC values ranging from 0.06 to $4 \mu \mathrm{g} / \mathrm{mL}$. Conversely, moderate activities against Gram-negative bacteria were observed in association with the efflux pump mechanism. ${ }^{76,}$ 101-103 This compound exhibited potent inhibitory activity targeting both FabF and FabH, two essential condensing ketoacyl-[acyl carrier protein (ACP)] synthase II compounds involved in fatty acid synthesis. ${ }^{93,101,106}$ The $\mathrm{IC}_{50}$ against the FabF and The FabH were between $4.58 \mu \mathrm{M}$ and $9.17 \mu \mathrm{M}$ respectively. ${ }^{76,101-102}$ This natural product was evaluated as a strong drug candidate due to its potent in vivo efficacy and complete absence of toxic side-effects. ${ }^{76}$

The synthesis pathway of Lipid A offers promising targets for new drugs, as it is involved in the viability/physiology/virulence of Gram-negative bacteria. It has been shown that the loss of Lipid A contributes to bacterial death and to increasing the antibiotic susceptibility of bacteria. $^{107-108}$ The inhibition of one of the first six enzymes of Kdo2-Lipid A synthesis has been shown to be lethal for $E$. coli $i^{109-110}$ and/or renders the bacteria susceptible to other antibiotics that normally do not penetrate the outer membrane. ${ }^{41,107,111-112}$

Thus, the strategy of identifying new Lpx inhibitors has a vital role in the development of new antimicrobial agents. $^{107}$ 
UDP-N-acetylglucosamine acyltransferase or LpxA is the first enzyme of LPS biosynthesis pathway that catalyzes the reversible transfer of R-3-hydroxy-acyl moiety from its donor acyl carrier protein $(\mathrm{ACP})$ thioester to the UDP-N-acetyl-glucosamine. This enzyme is necessary for bacterial survival and the absence of any homologous protein in humans renders it as a promising target for anti-bacterial drug development. ${ }^{113-116}$ Thus, LpxA is a well-conserved essential enzyme found in most Gram-negative bacteria such as E. coli, P. aeruginosa, $K$. pneumoniae and $S$. enterica serovar Typhimurium except for $A$. baumannii which can grow without LPS under laboratory growth conditions. ${ }^{116-117}$

In the last decade, only peptide inhibitors which could represent a potential tool for the development and the screening of compounds binding the LpxA enzyme have been reported. ${ }^{118}$ However, due to the lack of delivery system, these peptide inhibitors could not be considered as antibacterial agents targeting cytoplasmic LpxA. Thus, no LpxA inhibitor having antibacterial activity has been publicly disclosed ${ }^{119}$ since unrealistic due to their impossibility to cross bacterial membranes and their low stability towards proteases activity. ${ }^{120}$

The first peptide inhibitor with a high affinity to LpxA, called peptide 920 (NH2SSGWMLDPIAGKWSR-CO2H) was discovered by Williams et al. using a phage display and identified as potential inhibitor of $E$. coli LpxA (EcLpxA) with a Ki of $50 \mathrm{nM} .^{121}$ Thus, even if no antibiotic activity of peptide $\mathbf{9 2 0}$ was observed in vivo probably due to its inability to cross the membranes ${ }^{122}$ the enzymatic evidence revealed that this compound is a largely competitive inhibitor with respect to the substrate $R$-3-hydroxymyristoate-ACP but not with the substrate UDP-3-O(R-hydroxymyristoyl)-GlcNAc. ${ }^{116,}{ }^{121}$ It was suggested that peptide 920 interacts with LpxA in a region that overlaps mainly with the $R$-3-hydroxymyristoyl-ACP substrate-binding site observed in the crystal structure of the peptide 920-EcLpxA complex. ${ }^{121,123}$ Based on these assumptions, Dangkulwanich et al. designed a small library of peptides by varying the number of peptides involved and by using peptide $\mathbf{9 2 0}$ as a scaffold. 
Table 1 summarizes the results encountered with $\mathrm{IC}_{50}$ ranging from $50 \mathrm{nM}$ to $>100 \mu \mathrm{M}$. Thus, the peptides CR19-CR22 can be considered as potent hits for the design of LpxA inhibitors and CR20 $\left(\mathrm{IC}_{50}=50 \mathrm{nM}\right)$ appeared as the most effective inhibitor targeting LpxA mainly in the binding site of acyl-ACP (Table 1). Further experiments revealed that in the cocrystallization complex CR20-LpxA the peptide CR20 is more ordered in the active site of LpxA than peptide 920 and that its interaction with LpxA is secured by a majority of polar interactions mediated by water molecules. ${ }^{124}$

Table 1: Sequence and biological activity of identified LpxA peptide inhibitors

\begin{tabular}{ccc}
\hline Peptide & Sequence & IC $_{\mathbf{5 0}}$ \\
\hline Peptide 920 & SSGWMLDPIAGKWSR & $60 \pm 9 \mathrm{nM}$ \\
CR19 & GWMLDPIAGKWSR & $77 \pm 3 \mathrm{nM}$ \\
CR20 & WMLDPIAGKWSR & $50 \pm 6 \mathrm{nM}$ \\
CR21 & SSGWMLDPIAGKWS & $12 \pm 1.4 \mu \mathrm{M}$ \\
CR22 & SSGWMLDPIAGKW & $9 \pm 2.2 \mu \mathrm{M}$ \\
CR23 & GWMLDPIAGKW & $10 \pm 0.3 \mu \mathrm{M}$ \\
CR24 & GWMLDPIA & $>100 \mu \mathrm{M}$ \\
CR25 & WMLDPI & $>100 \mu \mathrm{M}$ \\
CR26 & WMLD & $>100 \mu \mathrm{M}$ \\
\hline
\end{tabular}

Despite the challenge of the peptide delivery into bacterial cytoplasm, Jenkins and Dotson have identified three peptides called RJPXD31, RJPXD33, RJPXD34 with ordered sequence QHFMVPDINDMQ-NH2, TNLYMLPKWDIP-NH2, SENNFMLPLLPL-NH2 respectively ${ }^{125}$ and even though these peptides exert potent antibacterial activity, they show poor bioavailability and susceptibility. ${ }^{126}$ Among them the most interesting was RJPXD33 presenting a dual specific affinity for LpxA and LpxD by competing with mutually exclusive manner with $R$-3-hydroxymyristoyl-ACP substrate and potentially inhibiting the two 
acyltransferases of E. coli. Thus, this peptide inhibits $\operatorname{LpxD}\left(\mathrm{K}_{\mathrm{D}}=6 \mu \mathrm{M}\right)$ and $\mathrm{LpxA}\left(\mathrm{K}_{\mathrm{D}}=\right.$ $20 \mu \mathrm{M})^{127}$ but is considered as a weaker inhibitor of EcLpxA compared to Peptide 920. ${ }^{122}$ It is noteworthy that to date and despite its relatively weak binding affinity and its lack of antibiotic activity in vitro, RJPXD33 remains an attractive lead scaffold for further optimization of peptidomimetics due to its dual specificity against two essential enzymes in the lipid A pathway. ${ }^{122}$

On the other hand, the crystal structure of EcLpxA in complex with RJPXD33 was determined at $1.9 \AA$ indicating that the peptide binds in a unique modality that mimics $(R)$ hydroxyacyl pantetheine (vitamin B5) binding to LpxA. By superposing the two complexes of EcLpxA-RJPXD33 and EcLpxD-RJPXD33, it was also noticed the presence of complementary peptide binding pocket within LpxD. ${ }^{120,}$ 122, 125

Otherwise, Kroeck et al developed a virtual screening of small zinc molecules ligands against P. aeruginosa LpxA and LpxD using a target-structure-based methodology performed by molecular docking surface plasmon resonance (SPR) bioanalysis and high-resolution X-ray crystallography. ${ }^{118}$ They successfully identified several compounds (5-9) able to bind the active site of LpxA in the acyl chain binding pocket such as compound $\mathbf{5}$ and $\mathbf{6}$ that are the first examples of small molecules presenting a specific affinity for LpxA and LpxD. Thus, it was demonstrated that the polar functional groups of $\mathbf{5}$ directly bind with backbone amide groups of LpxA and LpxD whereas the naphthalene moiety remains located in the hydrophobic pocket. Moreover, due to the slightly larger acyl-chain binding pocket in the case of LpxD the aromatic ring of the ligand sinks deeper into the LpxD structure than the LpxA one. ${ }^{118}$

Nevertheless, the binding affinities of $\mathbf{5}$ and $\mathbf{6}$ is low compared to RJPXD33 and Peptide 920, with $\mathrm{K}_{\mathrm{D}}$ ranging from 2.1 to $36.7 \mu \mathrm{M}$ (Figure 6) and preliminary studies indicated that no significant inhibition of the $P$. aeruginosa bacterial growth was observed even by using concentrations up to $256 \mu \mathrm{g} / \mathrm{mL}^{118}$ 
Figure 6. LpxA and LpxD inhibitors structure 5-15 $\left(\mathrm{ND}=\mathrm{K}_{\mathrm{D}}\right.$ not determined $)$

Recently, Han et al reported novel inhibitors of LpxA (Figure 6) issued from a screening of Novartis compound collection. These small molecules possessed an antibacterial activity against efflux pump-deficient $E$. coli $(\Delta$ tolC) with no obvious eukaryotic cell cytotoxicity or hemolysis at $100 \mu \mathrm{M}$. Unfortunately, they did not inhibit the growth of E. coli ATCC 25922 clinical isolate even at $128 \mu \mathrm{g} / \mathrm{mL}$ presenting an $\mathrm{IC}_{50}$ and $\mathrm{K}_{\mathrm{D}}$ of $1.4 \mu \mathrm{M}$ and $0.1 \mu \mathrm{M}$ for $\mathbf{1 0}$ and $4.8 \mu \mathrm{M}$ and $110 \mu \mathrm{M}$ for $\mathbf{1 1}$, respectively. ${ }^{119}$

In vitro assays confirmed that these compounds are LpxA inhibitors with an antibacterial activity mediated by the target inhibition but, intriguingly, by two distinct mechanisms of action. Thus, compound $\mathbf{1 0}$ acts by binding the apo form with a competitive inhibition to 3OH-acyl-ACP and a noncompetitive to UDP-GlcNAc, whereas compound 7 inhibits LpxA only in the presence of the product UDP-3-O-(R-3-hydroxymyristoyl)-GlcNAc. The X-ray co-structure of LpxA-6 demonstrated that the molecule binds to apo LpxA by blocking a large portion of the acyl chain binding pocket. On its side, compound 7 was demonstrated to bind the LpxA-product complex in a product-dependent manner. ${ }^{119}$

In $P$. aeruginosa, neither compound $\mathbf{1 0}$ nor compound $\mathbf{1 1}$ was active even at $128 \mu \mathrm{g} / \mathrm{mL}$. This is probably due to active site differences in $P$. aeruginosa LpxA that would impair the inhibitor binding. ${ }^{119}$

To improve the cellular activity against wild type $E$. coli strains, they designed and optimized several analogues of compound $\mathbf{1 1}$ which presented a favorable structure-based property against Gram-negative bacteria with higher solubility and lower $\log \mathrm{D}$ and molecular weight compared to compound 10. From the designed compounds, the most potent was the compound 12 (Figure 6) having an amino group on the pyridine ring and a MIC of $16 \mu \mathrm{g} / \mathrm{mL}$ against wild-type strains as well as an $\mathrm{IC}_{50}$ of $0.6 \mu \mathrm{M} .{ }^{119}$ Taken together, it was demonstrated that the introduction of three different functional groups (chloro, methoxy, and amino groups) resulted in an 8-fold improvement in both biochemical inhibition and antibacterial activity. ${ }^{119}$ 
Another virtual pharmacophore-based screening with various drug-likeliness filters and molecular docking have allowed to identify 3 LpxA inhibitors 13-15, efficient against Moraxella catarrhalis and that bind near to the catalytic base and make interactions with the key active site residues. ${ }^{113}$

Finally, it is crucial to mention that LpxA shares a homotrimer architecture and conserved active site features, especially in the acyl-chain binding pockets that reside in the dimer interface of the $\beta$-helix trimer core ${ }^{118}$ as well as functional similarities with $\operatorname{LpxD}$ that could confer dual targeting to inhibitors offering an opportunity of increased potency and reduced likelihood of resistance formation. ${ }^{118,125}$

\section{LpxC inhibitors}

Another attractive target consists of the UDP-3-O-(R-3-hydroxymyristoyl)-Nacetylglucosamine deacetylase or LpxC, a constitutively expressed enzyme present in the cytoplasm and exclusively conserved in Gram-negative bacteria. LpxC is a zinc-dependent hydrolase that catalyzes the deacetylation of UDP-3-O-(R-3-hydroxymyristoyl) GlcNAc, the second committed step in Lipid A synthesis (Figure 3). ${ }^{41,128-131}$ LpxC requires one or more zinc ions to be catalytically active and NMR and X-ray crystallography studies indicate that LpxC has a " $\beta-\alpha-\alpha-\beta$ sandwich" structure and encapsulates the acyl chain of the substrate with a unique hydrophobic passage. ${ }^{112,132}$ Many potent LpxC inhibitors have been identified, most of which contain a hydroxamate group that targets the catalytic zinc ion. ${ }^{133-137}$

In the late 1980s, screening achieved by Merck research laboratories identified the small oxazoline hydroxamic acid compound 16 (Figure 7) which exerts antimicrobial activity against E. coli strains with MIC values ranging from 200 to $400 \mu \mathrm{g} / \mathrm{mL}$ by inhibiting Lipid A synthesis and LPS production. ${ }^{132,138}$

Figure 7. Structure and biological activities of LpxC inhibitors 16-21 
Compound 16 was then selected and assayed individually against all nine enzymes involved in Lipid A synthesis. Interestingly, this compound showed a specific inhibition of LpxC activity with an $\mathrm{IC}_{50}=8.5 \mu \mathrm{M}$ for the $E$. coli enzyme and a $\mathrm{K}_{\mathrm{i}}$ of $24 \mu \mathrm{M} .{ }^{107,137-138}$

It has been reported that LpxC inhibitors with effective antimicrobial activity against Enterobacteriaceae and $P$. aeruginosa share two structural similarities consisting of the presence of a hydroxamic acid group binding unit and a linear and rigid lipophilic tail interacting with the enzyme hydrophobic tunnel occupied by the fatty acyl chain. ${ }^{109,131,139-140}$ More than 200 analogues of $\mathbf{1 6}$ have been synthesized, and the most efficient compound was identified as derivative 17 (Figure 7) which has a inhibition constant up to $50 \mathrm{nM}$ and significantly increases the potency 100 -fold due to the attachment of methoxy and electrondonating hydrophobic groups to the phenyl moiety. ${ }^{138} 141$ This compound was identified to be a potent inhibitor of $E$. coli $\mathrm{LpxC}$ with an $\mathrm{IC}_{50}$ of $30 \mathrm{nM}$ and $\mathrm{MIC}$ values against $E$. coli bacterial strains ranging from 1 to $3 \mu \mathrm{g} / \mathrm{mL}^{131,142}$ Unfortunately, LpxC inhibition is not a general phenomenom among different species such as P. aeruginosa or Aquifex aeolicus. ${ }^{107}$ It was shown that the molecule was active against a mutant of $P$. aeruginosa in which the envAl gene encoding LpxC was inactivated and replaced by the E. coli ortholog. In the same context, the E. coli mutant complemented with the $P$. aeruginosa lpxC gene was resistant towards the compound. To extend the LpxC inhibitor spectrum, Jackman et al. designed a series of substrate analogs incorporating a hydroxamic acid functional group. ${ }^{143-144}$ Thus, the most efficient compound labeled 18 (Figure 7) led to moderate inhibition of E. coli LpxC, with a $\mathrm{K}_{\mathrm{i}}$ value of $650 \mathrm{nM}^{145}(\mathrm{pH} 5.5-7.4)$, when it exhibits an excellent inhibitor activity against $A$. aeolicus enzyme with a $\mathrm{K}_{\mathrm{i}}$ of $1 \mathrm{nM}$ and $650 \mathrm{nM}$ at $\mathrm{pH} 7.4$ and 5.5, respectively. ${ }^{143 \text {, }}$ ${ }^{145}$ Nevertheless, while 18 LpxC inhibitors exhibited almost similar inhibition level among the Gram-negative strains including $P$. aeruginosa, this compound failed to demonstrate any attractive useable activity probably due its long hydrophobic acyl chain which limits its membrane diffusion. ${ }^{112,132,143}$ 
In 2003, more than 1200 hydroxamate-containing compounds were prepared by Andersen et al. and one of them, namely, 19 possessing a threonyl-hydroxamate head group, presented the best inhibition profile against $A$. aeolicus $\mathrm{LpxC} .^{132,137,146}$ It is also noteworthy that $\mathbf{1 9}$ is a powerful antibiotic against a wide range of Gram-negative pathogens such as ciprofloxacin or tobramycin. ${ }^{107,146,147-148}$ This was the first LpxC inhibitor capable of inhibiting the growth of P. aeruginosa with an $\mathrm{IC}_{50}<2.1 \mathrm{nM}^{137}$ Interestingly, Tan et al. evaluated the activity of colistin in combination with 19 against $P$. aeruginosa biofilms and observed synergistic activities at subinhibitory concentrations in vitro and in vivo ${ }^{149}$, using a checkerboard assay and biofilm conditions, synergy (FIC 0.34) was reported not only against colistin-susceptible P. aeruginosa biofilms but also resistant strains. ${ }^{149}$ To determine the role of efflux in modulating the susceptibility of $P$. aeruginosa to 19, Caughlan et al. compared wildtype PA01 with mutants lacking MexAB-OprM or MexXY-OprM efflux pumps and demonstrated that the deletion of mexB contributed to a 4-fold increase in susceptibility, suggesting that compound 19 is a substrate of the MexB pump. Conversely, mexXY deletion did not affect the susceptibility, whereas the simultaneous deletion of both genes led to a slightly larger shift (8fold). ${ }^{150}$ Furthermore, the X-ray structure analysis of co-crystals of LpxC and $\mathbf{1 9}$ showed the presence of a specific residue of the molecule located at the exit of the hydrophobic passage of LpxC. ${ }^{109,151}$

Sulfonamide derivatives of hydroxamic acid have been developed from the screening of a metalloenzyme inhibitor library and identified compound $\mathbf{2 0}$ that shows bactericidal properties against $E$. coli with almost 3-log killing in 4 h. ${ }^{133,152}$ Analyses of E. coli mutants showing a decreased susceptibility towards $\mathbf{2 0}$ indicated the emergence of resistance mutations in the $f a b Z$ gene involved in fatty acid assembly and in the $l p x C$ gene involved in Lipid A biosynthesis.

Recently, several biopharmaceutical companies such as Achaogen have conducted extensive research projects for the discovery of novel LpxC inhibitors. In this context, compound 21 
(Figure 7) was reported as one of the most promising molecules selected for a phase 1 human clinical trial. ${ }^{153-154}$ It presented significant activity against E. coli and P. aeruginosa PA01, with MIC values of $0.125-0.06 \mu \mathrm{g} / \mathrm{m}^{137}$ This compound was potent against $100 \%$ of the $P$. aeruginosa tested isolates with MIC values $\leq 2 \mu \mathrm{g} / \mathrm{mL} .{ }^{155}$ Nevertheless, even if 21 was active against a large panel of Gram-negative nosocomial bacteria, a failure of efficiency was noted against A. baumannii, B. cepacia and S. maltophilia bacterial strains, limiting its future development as a general antibiotic. ${ }^{137,154-155}$ The variations in observed susceptibility support the possibility of great enzyme flexibility rather than intrinsic resistance caused by a lack of penetration or efflux in the tested bacteria. ${ }^{141}$

\section{LpxD}

As well as the two first enzymes of lipid A biosynthesis, the UDP-3-O-(3hydroxymyristoyl)glucosamine $\mathrm{N}$-acyltransferase or LpxD is considered as an attractive target for novel antibiotics. ${ }^{156}$ This enzyme for which crystal structure was solved for $E$. coli and $P$. aeruginosa, catalyzes the third step of Lipid A biosynthesis e.g. the transfer of 3hydroxymyristic acid from the $R$-3-hydroxymyristoyl-acyl carrier protein to the 2-OH group of UDP-3-O-(3-Hydroxymyristoyl) glucosamine. ${ }^{157-158}$

First, we must cite the already mentioned peptide inhibitors RJPXD31 (QHFMVPDINDMQ$\mathrm{NH}_{2}$ ) and RJPXD33 (TNLYMLPKWDIP-NH${ }_{2}$ ) (targeting both LpxA and LpxD) as well as RJPXD34 (SENNFMLPLLPL-NH ${ }_{2}$ ) (exclusively binding LpxD) which led Jenkins to identify new small molecules inhibiting the $\mathrm{LpxD}$ reaction with an $\mathrm{IC}_{50}$ of $3.2 \mu \mathrm{M}$ and a MIC value of $3.13 \mu \mathrm{g} / \mathrm{mL}$ against $E$. coli TolC minus strain. ${ }^{120,156,159-160}$

Ma et al. reported recently that the aromatization of $\mathbf{2 2}$ lead to more stable oxidized compounds 23 demonstrating an improved antimicrobial activity against E. coli TolC minus strain with a MIC of $1 \mu \mathrm{g} / \mathrm{mL}$ whereas a MIC up to $128 \mu \mathrm{g} / \mathrm{mL}$ was observed against wild type strain (Figure 8). To ensure its effectiveness as a LpxD inhibitors, it was observed that the 
overexpression of $\operatorname{lpx} D$ gene in E. coli TolC minus increases the MIC of 23 by 8 -fold whereas overexpression of the rest of $l p x$ genes did not affect the susceptibility. ${ }^{161}$ Furthermore, it was determined by using SPR assay that compound $\mathbf{2 3}$ directly binds the E.coli apo-LpxD. ${ }^{161}$

Figure 8. Synthetic LpxD inhibitors 22-23 and potent natural LpxD inhibitors 24-32 Due to the adverse effect of synthetic molecules, the in silico study of Rath et al suggested that natural products such as ajoene $\mathbf{2 4}$, allicin $\mathbf{2 5}$, cinnamaldehyde $\mathbf{2 6}$, curcumin $\mathbf{2 7}$, neral $\mathbf{2 8}$, gallotannin 29, isoorientin 30, isovitexin 31 and vitexin 32 (Figure 8) with both anti-oxidant and antibacterial proprieties can be attractive hits in the search of $\mathrm{LpxD}$ inhibitors against Bordetella petrii. ${ }^{162}$ They demonstrated that isoorientin 30 was an appropriate candidate to target B. petrii LpxD, by contacting a strong interaction with the protein-ligand complex conferring its stability. ${ }^{162}$ Moreover, it was shown that this natural product was the lone molecule possessing a perfect balance between a high inhibitory effect and a lowest binding energy and inhibition constant. ${ }^{162}$

\section{LpxH}

UDP-diacylglucosamine pyrophosphohydrolase LpxH is the fourth enzyme of the lipid A biosynthesis pathway which catalyzes the formation of 2,3-diacylglucosamine 1-phosphate (Lipid X) and UMP. ${ }^{163-166}$ In 2015, Nayer et al. have successfully synthesized the first LpxH inhibitors as substituted sulfonyl piperazine and pyrazole derivatives such as $\mathbf{3 3}$ bearing a Nacetyl indoline group and presenting a weak antimicrobial activity against E. coli ATCC 25922 and $P$. aeruginosa PA01 (MICs up to $64 \mu \mathrm{g} / \mathrm{mL}$ ) whereas an important inhibitory effect was observed against E. coli ATCC 25922 TolC minus strain $(0.25 \mu \mathrm{g} / \mathrm{mL})$ (Figure 9). ${ }^{167}$ For further understanding dealing with the mechanism of action of $\mathbf{3 3}$, the genome of 15 mutant resistant E. coli MG1655 TolC minus strains were sequenced indicating only modifications of four amino acids namely G48, L84, F141 and R149 in the LpxH. ${ }^{167}$ The MIC of these mutants increased from 0.25 to $>128 \mu \mathrm{g} / \mathrm{mL}$. To define the potential of $\mathrm{LpxH}$ as a 
target of interest, Lee et al. synthesized series of sulfonyl piperazine LpxH inhibitors analogous to $\mathbf{3 3}$ leading to the strongest identified to date LpxH inhibitor $\mathbf{3 4}$ able to inhibit 74 $\%$ of the LpxH activity at a $1 \mu \mathrm{M}$ concentration whereas compound 33 demonstrated only an efficient rate of inhibition of $45 \%$ under the same experimental conditions. ${ }^{168}$

Figure 9. Synthetic LpxH inhibitors 33-37.

Recently, a diffusion disk assay suggested that $\mathbf{3 3}$ may be an effective inhibitor of $K$. pneumoniae $\mathrm{LpxH}^{169}$ and Kwak et al. report the crystal structure of $K$. pneumoniae LpxH/33 complex. ${ }^{170}$ It was reported that the modification of the phenyl or $\mathrm{N}$-acyl indoline groups of 34 lead to compounds able to inhibit the LpxH of $K$. pneumoniae at low concentration $(0.1$ $\mu \mathrm{M})$. Additionally, Bohl et al. found an $\mathrm{IC}_{50}$ of $1.2 \pm 0.2 \mu \mathrm{M}$ for 33 against LpxH-mCherry and demonstrated its ability to block the conversion of UDP-DAG to Lipid X. ${ }^{171}$ Importantly, it was encountered that $\mathbf{3 3}$ was unable to inhibit the LpxH of $H$. influenzae and P.aeruginosa even at high concentration up to $100 \mu \mathrm{M} .{ }^{169}$ This may suggest an intrinsic non-susceptibility due to difference in the target site or lack to reach the internal concentration required for action (by permeability barrier or efflux pump).

Recently, among the extended $\mathrm{N}$-acyl chain analogs, the compound $\mathbf{3 5}$ lead to the strongest inhibition of LpxH activity with $64 \%$ which slightly close to the most active compound with phenyl group such as $\mathbf{3 6}$ and 37 leading to an inhibition of 79 and $48 \%$, respectively. ${ }^{172}$ Compound 35 appeared as the most efficient with a MIC value against K. pneumoniae of 1.6 $\mu \mathrm{g} / \mathrm{mL}$ higher than that encountered for $\mathbf{3 3}$ and slightly close to that of $\mathbf{3 4}$ ranging from 64 and $2.8 \mu \mathrm{g} / \mathrm{mL}$, respectively (Figure 9). ${ }^{169,172}$

Even if some promising inhibitors of the Lipid A biosynthesis pathway have been discovered some others Lpx enzymes such as LpxB, M also constitute a promising way for finding novel antibiotics against Gram-negative.

\section{Conclusion}


Lipid A is a key membrane component that plays a role during the biogenesis of bacterial OM where it strongly interacts with other membrane partners such as porins, architectural proteins, export systems, etc, in the external lipid bilayer. In this location, it contributes to the stringent permeability properties of outer membrane with respect to many toxic molecules, including antibiotics, defensins, disinfectants, detergents, etc. Due to these multiple involvements in crucial bacterial events, Lipid A has been recently suggested as an original target for the development of new antibacterial agents as outlined in Figure 10.

Figure 10. Potent strategies targeting Lipid A for the development of new antibacterial agents and possible bacterial resistance mechanisms.

One of the first molecule reported acting on lipid A biosynthesis, cerulenin, affects the early steps of its synthesis and although not clinically used some resistance mechanisms have been described anticipating the emergence of bacterial response against a possible therapy. In a different aspect, two macrocyclic peptides thanatin and murepavadin that has a high effect on Pseudomonas, target the LPS transport pathway via interaction with Lpt A, LptD, and other partners, involved in the addressing of newly synthesized LPS to OM. ${ }^{173}$ Interestingly, Luther et al. have recently generated hybrids using a polymyxin part fused to murepavadin derivatives ${ }^{174}$ that are active against Gram-negative bacteria. Sousa et al. discussed these important breakthroughs in the view of new molecules able to destabilize the assembly machinery of $\mathrm{OM}$ components of Gram-negative bacteria showing resistance to usual antibiotics. $^{175}$

Another possible target is the flippase MsbA involved in the IM translocation of nascent LPS chains. ${ }^{173}$ Regarding this point, it must be noted that ATP is the energy driving force of the machinery and possible inhibitors may induce some side effect on eucaryotic transporters and mitocondria physiology. Consequently, the dose-effect relationship must be studied with special attention for this compound group for future clinic development. 
Regarding the recent molecules, platensimycin and platencin, their antibacterial activity is impaired by expression of membrane efflux pumps that expel the drug. ${ }^{76}$ Importantly, the producer, Streptomyces platensis, exhibits different resistance mechanisms against these molecules and these mechanisms may appear during clinical use requiring specific attention for use. ${ }^{176}$ Recent assays using encapsulated-platensimycin suggest that this delivery process strongly increases the antibacterial activity against S. aureus. ${ }^{177}$ Descriptions of $\mathrm{LpxC}$ inhibitor resistant strains have been significantly scarce in terms of antibiotics resistance. ${ }^{137}$, ${ }^{178}$ The development of this king of specific cargo to ensure the intrabacterial delivery can be an attractive way for this candidate medicament but additional assays are required to define the appropriate capsule and their innocuity.

It is important to mention that these new antimicrobial agents face some efficient resistance mechanisms such as efflux or impermeability, developed by Gram-negative bacteria against clinically used antibiotics, which confer a partial or complete protection. From to this key observation, it must be mentioned that two ways could be envisaged for this new type of antibacterial weapons, - a direct effect on bacterial physiology linked to membrane roles of Lipid A, or - a facilitator effect such a combination with usual antibiotic for restoring its antibacterial effect on resistant bacteria.

Polymyxin molecules and squalamine have been previously used in combination with different antibiotics, for treatment and for identification of resistance mechanisms: the attempt being to increase outer membrane permeability facilitating the penetration and bypassing the membrane associated mechanism of resistance that impaired internal antibiotic concentration. Considering the large clinical use of bi-therapy based on $\beta$-lactams associated with $\beta$ lactamase inhibitor to treat B-lactamase producer strains, the association of efflux pump inhibitor to antibiotic to impaired efflux resistance activity proposed during recent years, or the recent murepavadin-polymyxin hydrids. ${ }^{174}$ The combination of a drug that target Lipid A with usual antibiotic can be an attractive way to restore antibacterial action in resistant 
bacteria. Conjoint synergy between the partners can be also studied for improving antibacterial action. Covalent link or association of the two entities depends on the target location in the bacterial cell, membrane, periplasm, cytoplasm and can be select appropriately. Regarding OM biogenesis, it is also possible to target the bacterial machinery involved in the OM proteins assembly, Bam system, as recently mentioned. ${ }^{173}$ However, similarly to lipid A synthesis/assembly, the bacterial adaptation must be carefully examined and again, the combination could be promising depending on the bacterial species and the antibiotic partner. Importantly, the measure of internal concentration of active molecules is now possible by using appropriate methods (spectrofluorimetry or mass spectrometry). ${ }^{24}$ This point is strategic for the determination of respective concentration used in combination for anticipating future toxic aspects or selection of resistance mechanisms. In this aspect, various detector-regulators cascades (e.g. TCS, HTH, etc.) are present in bacterial cell envelope and cytoplasm, including sensors, transmitters, regulators. ${ }^{179}$ These sophisticated systems can sense the presence of toxic compounds or their deleterious action on bacterial physiology and trigger an adaptative response to protect against the antibacterial activity. Consequently, the dose use is a critical point for a non-selective treatment which can induce the emergence of resistance respectively to the involved pathogens.

The divergence in the antibacterial activity observed between the new compounds described previously also reflects the variation in the structure of the target exhibited in the various bacterial species. Moreover, the conditions that exist in the infectious sites, e.g., pH, osmotic pressure, salt concentration, etc., contribute to the modulation of the biosynthesis cascade and final structure of lipid A. Thus, these key parameters can alter the bacterial susceptibility to compounds and ask for an adapted chemotherapy. Interestingly, this may present an ecological advantage by having a species selectivity the molecule will not target the bacteria belonging to usual microflora and will not affect the natural microbiome. This strongly argues for a personalized antibacterial strategy preserving the balance of human flora. 
After several decades of prominent position of membrane proteins for the research and development of antibacterial agents, the lipid A can pave the ways to define appropriate pharmaco-association, or -modulation, of various molecules that can be used for generating “intelligent antibiotic" strategies of the future.

\section{Ancillary Information}

\section{Supporting Information}

Table S1: MIC values of platensimycin and platencin against Gram-positive and Gramnegative bacteria

Figure S1: Lipid A chemical structure for different Gram-negative bacteria

Figure S2: A) Chemical biphosphate analogue of E. coli-type Lipid A B) Effects of structural modifications ( $\mathrm{OH}->\mathrm{H}, \mathrm{P}->\mathrm{H}, \mathrm{O}->\mathrm{OH}, \mathrm{P}->\mathrm{H})$ of E. coli Lipid A on biological activity. C) Effects of acyl modifications of E. coli Lipid A on biological activity.

\section{Corresponding Author}

*Address: UMR-MD1, U1261 INSERM, «Membranes et Cibles Thérapeutiques》, Faculté de pharmacie, 27 boulevard Jean Moulin, 13385 Marseille cedex 05, France. Tel.: $(+33)$ 689271645. E-mail: bruneljm@yahoo.fr.

\section{ORCID}

Jean Michel Brunel: 0000-0002-9355-8980

\section{Author Contributions}

The authors declare to contribute equally to this work.

\section{Biographies}

Azza Troudi was born in Tunis, Tunisia. She obtained her engineering diploma from the Polytechnic Institute, Free University of Tunis (Tunisia) in 2017 and her master degree from the Faculty of Medecine, Rennes (France) in 2018. She is currently a PhD student at the Faculty of Pharmacy of Marseille (France), (UMR-MD1, U1261 INSERM) and the Faculty of 
sciences of Tunis (Tunisia) (LMBA- LR03ES03) under the joint supervision of Dr. J. M. Brunel and Dr. N. Klibi.

Jean Marie Pagès, Emeritus Research Director at INSERM (Institut National de la Santé et de la Recherche Médicale) is member of the research Unit "Membranes and Therapeutic targets", Medical Campus Aix-Marseille University France. He was previously Chair of the UMR-MD1 from 2008 to 2017. He studies the bacterial membrane, from genetic regulation, biological activities to clinical aspects and the role of outer membrane porins and drug efflux pumps in bacterial adaptation. He developed original methods to understand the antibiotic translocation across membranes and the molecular bases of resistance in Gram-negative bacteria. He has published over 300 papers and abstracts in international journals (Nature Microbiology, PNAS, JBiolChem, JMedChem) and presented his work and concepts during several International meetings (Gordon Research Conferences, Nature Conferences, ECCMID, ICAAC).

Jean Michel Brunel was born in Marseille, France. He graduated from the School of Chemistry of Marseille (ESCM) in 1991. He obtained his Ph.D. degree in 1994 from Aix Marseille III University in the field of enantioselective synthesis and organophosphorus chemistry. In 1994, he joined the group of Pr. H. B. Kagan (UniversitéParis Sud) as a postdoctoral fellow working on the enantioselective catalytic oxidation of sulfides (1994-1996). In 1997, he joined the CNRS as Chargé de Recherche and is now working with the faculty of pharmacy (UMR-MD1, U1261 INSERM). His research program is focused on the development of novel synthetic methods in organic chemistry as well as the synthesis of new classes of antimicrobial agents.

\section{Abbreviations used}

OM, Outer Membrane; IM, Inner Membrane; Kdo, 3-Deoxy-d-Manno-Oct-Ulosonic Acid; CAMPS, Cationic Antimicrobial Peptides; KAS, $\beta$-KetoAcyl-ACP Synthases.

\section{References}


1. Rollauer, S. E.; Sooreshjani, M. A.; Noinaj, N.; Buchanan, S. K., Outer membrane protein biogenesis in Gram-negative bacteria. Philos. Trans. R. Soc. London, Ser. B 2015, 370 (1679), 20150023.

2. Nikaido, H., Molecular basis of bacterial outer membrane permeability revisited. Microbiol. Mol. Biol. Rev. 2003, 67 (4), 593-656.

3. Simpson, B. W.; Trent, M. S., Pushing the envelope: LPS modifications and their consequences. Nat. Rev. Microbiol. 2019, 17 (7), 403-416.

4. Delcour, A. H., Outer membrane permeability and antibiotic resistance. Biochim. Biophys. Acta 2009, 1794 (5), 808-816.

5. Masi, M.; Réfregiers, M.; Pos, K. M.; Pagès, J.-M., Mechanisms of envelope permeability and antibiotic influx and efflux in Gram-negative bacteria. Nature Microbiol. 2017, 2 (3), 1-7.

6. Reeves, P., Role of O-antigen variation in the immune response. Trends Microbiol. 1995, 3 (10), 381-6.

7. Lerouge, I.; Vanderleyden, J., O-antigen structural variation: mechanisms and possible roles in animal/plant-microbe interactions. FEMS Microbiol. Rev. 2002, 26 (1), 17-47.

8. Kalynych, S.; Morona, R.; Cygler, M., Progress in understanding the assembly process of bacterial O-antigen. FEMS Microbiol. Rev. 2014, 38 (5), 1048-1065.

9. Clifton, L. A.; Skoda, M. W. A.; Daulton, E. L.; Hughes, A. V.; Le Brun, A. P.; Lakey, J. H.; Holt, S. A., Asymmetric phospholipid: lipopolysaccharide bilayers; a Gramnegative bacterial outer membrane mimic. J. R. Soc. Interface 2013, 10 (89), 20130810.

10. Mateo, C. R.; Gómez, J.; Villalaín, J.; Ros, J. M. G., Protein-Lipid Interactions: New Approaches and Emerging Concepts. 2008; p 260.

11. Fairman, J. W.; Noinaj, N.; Buchanan, S. K., The structural biology of $\beta$-barrel membrane proteins: a summary of recent reports. Curr. Opin. Struct. Biol. 2011, 21 (4), 523531. 
12. Silhavy, T. J.; Kahne, D.; Walker, S., The bacterial cell envelope. Cold Spring Harb. Perspect. Biol. 2010, 2 (5), a000414.

13. Terashima, H.; Kawamoto, A.; Morimoto, Y. V.; Imada, K.; Minamino, T., Structural differences in the bacterial flagellar motor among bacterial species. Biophys. Physicobiol. 2017, 14, 191-198.

14. Burrows, L. L., Pseudomonas aeruginosa twitching motility: type IV pili in action. Annu. Rev. Microbiol. 2012, 66 (1), 493-520.

15. Stock, J., Mechanisms of receptor function and the molecular biology of information processing in bacteria. Bioessays 1987, 6 (5), 199-203.

16. Vogt, J.; Schulz, G. E., The structure of the outer membrane protein OmpX from Escherichia coli reveals possible mechanisms of virulence. Structure 1999, 7 (10), 1301-1309. 17. Beveridge, T. J., Structures of Gram-negative cell walls and their derived membrane vesicles. J. Bacteriol. 1999, 181 (16), 4725-4733.

18. Eichenberger, E. M.; Thaden, J. T., Epidemiology and mechanisms of resistance of extensively drug resistant Gram-negative bacteria. Antibiotics 2019, 8 (2), 37.

19. Ruppé, É.; Woerther, P.-L.; Barbier, F., Mechanisms of antimicrobial resistance in Gram-negative bacilli. Ann. Intensive Care 2015, 5, 21.

20. Miller, S. I., Antibiotic resistance and regulation of the Gram-negative bacterial outer membrane barrier by host innate immune molecules. mBio 2016, 7 (5), e01541-16.

21. Pagès, J.-M.; James, C. E.; Winterhalter, M., The porin and the permeating antibiotic: a selective diffusion barrier in Gram-negative bacteria. Nat. Rev. Microbiol. 2008, 6 (12), 893-903.

22. Lambert, P. A., Bacterial resistance to antibiotics: modified target sites. Adv. Drug Del. Rev. 2005, 57 (10), 1471-1485. 
23. Pang, Z.; Raudonis, R.; Glick, B. R.; Lin, T.-J.; Cheng, Z., Antibiotic resistance in Pseudomonas aeruginosa: mechanisms and alternative therapeutic strategies. Biotechnol. Adv. 2019, 37 (1), 177-192.

24. Vergalli, J.; Atzori, A.; Pajovic, J.; Dumont, E.; Malloci, G.; Masi, M.; Vargiu, A. V.; Winterhalter, M.; Réfrégiers, M.; Ruggerone, P.; Pagès, J.-M., The challenge of intracellular antibiotic accumulation, a function of fluoroquinolone influx versus bacterial efflux. Commun. Biol. 2020, 3 (1), 1-12.

25. Vergalli, J.; Dumont, E.; Cinquin, B.; Maigre, L.; Pajovic, J.; Bacqué, E.; Mourez, M.; Réfrégiers, M.; Pagès, J.-M., Fluoroquinolone structure and translocation flux across bacterial membrane. Sci. Rep. 2017, 7 (1), 9821.

26. Steimle, A.; Autenrieth, I. B.; Frick, J.-S., Structure and function: Lipid A modifications in commensals and pathogens. Int. J. Med. Microbiol. 2016, 306 (5), 290-301.

27. Alexander, C.; Rietschel, E. T., Invited review: Bacterial lipopolysaccharides and innate immunity. J. Endotoxin Res. 2001, 7 (3), 167-202.

28. Rietschel, E. T.; Kirikae, T.; Schade, F. U.; Mamat, U.; Schmidt, G.; Loppnow, H.; Ulmer, A. J.; Zähringer, U.; Seydel, U.; Di Padova, F.; Schreier, M.; Brade, H., Bacterial endotoxin: molecular relationships of structure to activity and function. FASEB J. 1994, 8 (2), 217-225.

29. Reeves, P. R.; Cunneen, M. M., Chapter 18 - Biosynthesis of O-antigen chains and assembly. In Microbia Glycobiology, 2010; pp 319-335.

30. Caroff, M.; Karibian, D.; Cavaillon, J.-M.; Haeffner-Cavaillon, N., Structural and functional analyses of bacterial lipopolysaccharides. Microb. Infect. 2002, 4 (9), 915-926.

31. Caroff, M.; Karibian, D., Structure of bacterial lipopolysaccharides. Carbohydr. Res. 2003, 338 (23), 2431-2447. 
32. Rietschel, E. T.; Wollenweber, H.-W.; Zähringer, U.; Lüderitz, O., Lipid A, the lipid component of bacterial lipopolysaccharides: Relation of chemical structure to biological activity. Klin. Wochenschr. 1982, 60 (14), 705-709.

33. Galanos, C.; Freudenberg, M. A., Bacterial endotoxins: biological properties and mechanisms of action. Mediators Inflamm. 1993, 2 (7), S11-S16.

34. Raetz, C. R. H.; Reynolds, C. M.; Trent, M. S.; Bishop, R. E., Lipid A modification systems in Gram-negative bacteria. Annu. Rev. Biochem. 2007, 76 (1), 295-329.

35. Matsuura, M.; Kojima, Y.; Yuzuru Homma, J.; Kubota, Y.; Yamamoto, A.; Kiso, M.; Hasegawa, A., Biological activities of chemically synthesized analogues of the nonreducing sugar moiety of lipid A. FEBS Lett. 1984, 167 (2), 226-230.

36. Westphal, O.; Lüderitz, O.; Galanos, C.; Mayer, H.; Rietschel, E. T., The story of bacterial endotoxin. In Adv. immunopharmacol., 1986; pp 13-34.

37. Westphal, O.; Lüderitz, O., Chemical research of lipopolysaccharides Gram negative bacteria. Angew. Chem. 1954, 66 (13-14), 407-417.

38. Anandan, A.; Vrielink, A., Structure and function of lipid A-modifying enzymes. Ann. N.Y. Acad. Sci. 2020, 1459 (1), 19-37.

39. Guest, R. L.; Rutherford, S. T.; Silhavy, T. J., Border control: Regulating LPS biogenesis. Trends Microbiol. 2020, in press.

40. Kim, S.; Patel, Dhilon S.; Park, S.; Slusky, J.; Klauda, Jeffery B.; Widmalm, G.; Im, W., Bilayer properties of lipid a from various Gram-negative bacteria. Biophys. J. 2016, 111 (8), 1750-1760.

41. Raetz, C. R. H.; Whitfield, C., Lipopolysaccharide endotoxins. Annu. Rev. Biochem 2002, 71, 635-700.

42. Moran, A., Lipopolysaccharide in bacterial chronic infection: Insights from Helicobacter pylori lipopolysaccharide and lipid A. Int. J. Med. Microbiol. 2007, 297 (5), 307-319. 
43. Bertani, B.; Ruiz, N., Function and biogenesis of lipopolysaccharides. EcoSal Plus 2018, $8(1)$.

44. Xiao, X.; Sankaranarayanan, K.; Khosla, C., Biosynthesis and structure-activity relationships of the lipid a family of glycolipids. Curr. Opin. Chem. Biol. 2017, 40, 127-137.

45. Emiola, A.; George, J.; Andrews, S. S., A Complete pathway model for lipid a biosynthesis in Escherichia coli. PLoS One 2015, 10 (4), e0121216.

46. Kadrmas, J. L.; Raetz, C. R. H., Enzymatic synthesis of lipopolysaccharide in Escherichia coli purification and properties of heptosyltransferase I. J. Biol. Chem. 1998, 273 (5), 2799-2807.

47. Sultan, I.; Rahman, S.; Jan, A. T.; Siddiqui, M. T.; Mondal, A. H.; Haq, Q. M. R., Antibiotics, resistome and resistance mechanisms: a bacterial perspective. Front. Microbiol. 2018, 9, 2066.

48. Vaara, M., Agents that increase the permeability of the outer membrane. Microbiol. Rev. 1992, 56 (3), 395-411.

49. Hancock, R. E.; Bell, A., Antibiotic uptake into Gram-negative bacteria. Eur. J. Clin. Microbiol. Infect. Dis. 1988, 7 (6), 713-720.

50. Tsujimoto, H.; Gotoh, N.; Nishino, T., Diffusion of macrolide antibiotics through the outer membrane of Moraxella catarrhalis. J. Infect. Chemother. 1999, 5 (4), 196-200.

51. Vázquez-Laslop, N.; Mankin, A. S., How Macrolide Antibiotics Work. Trends Biochem. Sci 2018, 43 (9), 668-684.

52. Peterson, A. A.; Fesik, S. W.; McGroarty, E. J., Decreased binding of antibiotics to lipopolysaccharides from polymyxin-resistant strains of Escherichia coli and Salmonella typhimurium. Antimicrob. Agents Chemother. 1987, 31 (2), 230-237.

53. Samantha, A.; Vrielink, A., Lipid A Phosphoethanolamine transferase: Regulation, structure and immune response. J. Mol. Biol. 2020. 
54. Vaara, M.; Fox, J.; Loidl, G.; Siikanen, O.; Apajalahti, J.; Hansen, F.; Frimodt-Møller, N.; Nagai, J.; Takano, M.; Vaara, T., Novel polymyxin derivatives carrying only three positive charges are effective antibacterial agents. Antimicrob. Agents Chemother. 2008, 52 (9), 3229-3236.

55. Vaara, M.; Vaara, T.; Jensen, M.; Helander, I.; Nurminen, M.; Rietschel, E. T.; Mäkelä, P. H., Characterization of the lipopolysaccharide from the polymyxin-resistant pmrA mutants of Salmonella typhimurium. FEBS Lett. 1981, 129 (1), 145-149.

56. Olaitan, A. O.; Morand, S.; Rolain, J.-M., Mechanisms of polymyxin resistance: acquired and intrinsic resistance in bacteria. Front. Microbiol. 2014, 5, 643.

57. Han, M.-L.; Velkov, T.; Zhu, Y.; Roberts, K. D.; Le Brun, A. P.; Chow, S. H.; Gutu, A. D.; Moskowitz, S. M.; Shen, H.-H.; Li, J., Polymyxin-induced lipid a deacylation in Pseudomonas aeruginosa perturbs polymyxin penetration and confers high-level resistance. ACS Chem. Biol. 2018, 13 (1), 121-130.

58. Mancilla-Becerra, L. M.; Lías-Macías, T.; Ramírez-Jiménez, C. L.; León, J. B., Multidrug-resistant bacterial foodborne pathogens: impact on human health and economy. Pathogenic Bacteria 2019.

59. Moffatt, J. H.; Harper, M.; Boyce, J. D., Mechanisms of polymyxin resistance. Adv. Exp. Med. Biol. 2019, 1145, 55-71.

60. Klein, G.; Raina, S., Regulated assembly of lps, its structural alterations and cellular response to lps defects. Int. J. Mol. Sci. 2019, 20 (2), 356.

61. Loutet, S. A.; Mussen, L. E.; Flannagan, R. S.; Valvano, M. A., A two-tier model of polymyxin B resistance in Burkholderia cenocepacia. Environ. Microbiol. Rep. 2011, 3 (2), 278-285.

62. Rosenfeld, Y.; Shai, Y., Lipopolysaccharide (Endotoxin)-host defense antibacterial peptides interactions: Role in bacterial resistance and prevention of sepsis. Biochim. Biophys. Acta 2006, 1758 (9), 1513-1522. 
63. Vaara, M.; Nurminen, M., Outer membrane permeability barrier in Escherichia coli mutants that are defective in the late acyltransferases of lipid a biosynthesis. Antimicrob. Agents Chemother. 1999, 43 (6), 1459-1462.

64. Powers, M.; Trent, M., Phospholipid retention in the absence of asymmetry strengthens the outer membrane permeability barrier to last-resort antibiotics. Proc. Natl. Acad. Sci. 2018, 115, 201806714.

65. Hamad, M. A.; Di Lorenzo, F.; Molinaro, A.; Valvano, M. A., Aminoarabinose is essential for lipopolysaccharide export and intrinsic antimicrobial peptide resistance in Burkholderia cenocepacia. Mol. Microbiol. 2012, 85 (5), 962-974.

66. Sutterlin, H. A.; Shi, H.; May, K. L.; Miguel, A.; Khare, S.; Huang, K. C.; Silhavy, T. J., Disruption of lipid homeostasis in the Gram-negative cell envelope activates a novel cell death pathway. Proc. Natl. Acad. Sci. 2016, 113 (11), E1565-E1574.

67. Sperandeo, P.; Dehò, G.; Polissi, A., The lipopolysaccharide transport system of Gram-negative bacteria. Biochim. Biophys. Acta 2009, 1791 (7), 594-602.

68. Collet, J.-F.; Cho, S.-H.; Iorga, B. I.; Goemans, C. V., How the assembly and protection of the bacterial cell envelope depend on cysteine residues. J. Biol. Chem. 2020, 295 (34) 11984-11994.

69. Whitfield, C.; Williams, D. M.; Kelly, S. D., Lipopolysaccharide O-antigens bacterial glycans made to measure. J. Biol. Chem. 2020, 295 (31), 10593-10609

70. Sherman, D. J.; Okuda, S.; Denny, W. A.; Kahne, D., Validation of inhibitors of an $\mathrm{ABC}$ transporter required to transport lipopolysaccharide to the cell surface in Escherichia coli. Biorg. Med. Chem. 2013, 21 (16), 11.

71. Khalid, S.; Piggot, T. J.; Samsudin, F., Atomistic and coarse grain simulations of the cell envelope of gram-negative bacteria: what have we learned? Acc. Chem. Res. 2018.

72. Epand, R. M.; Epand, R. F., Lipid domains in bacterial membranes and the action of antimicrobial agents. Biochim. Biophys. Acta 2009, 1788 (1), 289-294. 
73. Ghai, I.; Ghai, S., Understanding antibiotic resistance via outer membrane permeability. Infect. Drug Resist. 2018, 11, 523-530.

74. Poole, K., Efflux pumps as antimicrobial resistance mechanisms. Ann. Med. 2007, 39 (3), 162-176.

75. Heath, R. J.; White, S. W.; Rock, C. O., Inhibitors of fatty acid synthesis as antimicrobial chemotherapeutics. Appl. Microbiol. Biotechnol. 2002, 58 (6), 695-703.

76. Wang, J.; Kodali, S.; Lee, S. H.; Galgoci, A.; Painter, R.; Dorso, K.; Racine, F.; Motyl, M.; Hernandez, L.; Tinney, E.; Colletti, S. L.; Herath, K.; Cummings, R.; Salazar, O.; González, I.; Basilio, A.; Vicente, F.; Genilloud, O.; Pelaez, F.; Jayasuriya, H.; Young, K.; Cully, D. F.; Singh, S. B., Discovery of platencin, a dual FabF and FabH inhibitor with in vivo antibiotic properties. Proc. Natl. Acad. Sci. 2007, 104 (18), 7612-7616.

77. Zheng, Z.; Parsons, J. B.; Tangallapally, R.; Zhang, W.; Rock, C. O.; Lee, R. E., Discovery of novel bacterial elongation condensing enzyme inhibitors by virtual screening. Bioorg. Med. Chem. Lett. 2014, 24 (11), 2585-2588.

78. Yao, J.; Rock, C. O., Bacterial fatty acid metabolism in modern antibiotic discovery. Bioch. Biophys. Acta. Mol. Cell. Biol. Lip. 2017, 1862 (11), 1300-1309.

79. Müller-Loennies, S.; Lindner, B.; Brade, H., Structural analysis of deacylated lipopolysaccharide of Escherichia coli strains 2513 (R4 core-type) and F653 (R3 core-type). Eur. J. Biochem. 2002, 269 (23), 5982-5991.

80. Trajtenberg, F.; Altabe, S.; Larrieux, N.; Ficarra, F.; de Mendoza, D.; Buschiazzo, A.; Schujman, G. E., Structural insights into bacterial resistance to cerulenin. The FEBS journal 2014, 281 (10), 2324-2338.

81. Bommineni, G. R.; Kapilashrami, K.; Cummings, J. E.; Lu, Y.; Knudson, S. E.; Gu, C.; Walker, S. G.; Slayden, R. A.; Tonge, P. J., Thiolactomycin-based inhibitors of bacterial $\beta$-ketoacyl-ACP synthases with in vivo activity. J. Med. Chem. 2016, 59 (11), 5377-5390. 
82. Kodali, S.; Galgoci, A.; Young, K.; Painter, R.; Silver, L. L.; Herath, K. B.; Singh, S. B.; Cully, D.; Barrett, J. F.; Schmatz, D.; Wang, J., Determination of selectivity and efficacy of fatty acid synthesis inhibitors. J. Biol. Chem. 2005, 280 (2), 1669-1677.

83. Omura, S., The antibiotic cerulenin, a novel tool for biochemistry as an inhibitor of fatty acid synthesis. Bacteriol. Rev. 1976, 40 (3), 681-697.

84. Matsumae, A.; Nomura, S.; Hata, T., Studies on cerulenin. iv. biological characteristics of cerulenin. J. Antibiot. 1964, 17, 1-7.

85. Miyakawa, S.; Suzuki, K.; Noto, T.; Harada, Y.; Okazaki, H., Thiolactomycin, a new antibiotic. IV. Biological properties and chemotherapeutic activity in mice. J. Antibiot. 1982, 35 (4), 411-419.

86. Noto, T.; Oishi, H.; Endo, H.; Okazaki, H., A new antibiotic 111. In vitro antibacterial activity. J. Antibiot. 1982, 35 (4), 401-410.

87. Oishi, H.; Noto, T.; Sasaki, H.; Suzuki, K.; Hayashi, T.; Okazaki, H.; Ando, K.; Sawada, M., Thiolactomycin, a new antibiotic. I. Taxonomy of the producing organism, fermentation and biological properties. J. Antibiot. 1982, 35 (4), 391-395.

88. Omura, S., The antibiotic cerulenin, a novel tool for biochemistry as an inhibitor of fatty acid synthesis. Bacteriol. Rev. 1976, 40 (3), 681-697.

89. Omura, S., Cerulenin. Methods Enzymol. 1981, 72, 520-532.

90. Heath, R. J.; White, S. W.; Rock, C. O., Lipid biosynthesis as a target for antibacterial agents. Prog. Lipid Res. 2001, 40 (6), 467-497.

91. Price, A. C.; Choi, K. H.; Heath, R. J.; Li, Z.; White, S. W.; Rock, C. O., Inhibition of beta-ketoacyl-acyl carrier protein synthases by thiolactomycin and cerulenin. Structure and mechanism. J. Biol. Chem. 2001, 276 (9), 6551-6559.

92. Heath, R. J.; Rock, C. O., Fatty acid biosynthesis as a target for novel antibacterials. Curr. Opin. Investig. Drugs 2004, 5 (2), 146-53. 
93. Das, M.; Sakha Ghosh, P.; Manna, K., A review on platensimycin: A selective FabF Inhibitor. Int. J. Med. Chem. 2016, 2016, 9706753.

94. Adhikari, R. P.; Novick, R. P., Subinhibitory cerulenin inhibits staphylococcal exoprotein production by blocking transcription rather than by blocking secretion. Microbiology 2005, 151 (Pt 9), 3059-3069.

95. Parsons, J. B.; Rock, C. O., Bacterial lipids: Metabolism and membrane homeostasis. Prog. Lipid Res. 2013, 52 (3), 249-276.

96. Hayashi, T.; Yamamoto, O.; Sasaki, H.; Kawaguchi, A.; Okazaki, H., Mechanism of action of the antibiotic thiolactomycin inhibition of fatty acid synthesis of Escherichia coli. Biochem. Biophys. Res. Commun. 1983, 115 (3), 1108-1113.

97. Sasaki, H.; Oishi, H.; Hayashi, T.; Matsuura, I.; Ando, K.; Sawada, M., Thiolactomycin, a new antibiotic. II. Structure elucidation. J. Antibiot. 1982, 35 (4), 396-400. 98. Kamal, A.; Azeeza, S.; Malik, M. S.; Shaik, A. A.; Rao, M. V., Efforts towards the development of new antitubercular agents: potential for thiolactomycin based compounds. $J$. Pharm. Pharm. Sci. 2008, 11 (2), 56s-80s.

99. Noto, T.; Miyakawa, S.; Oishi, H.; Endo, H.; Okazaki, H., Thiolactomycin, a new antibiotic. J. Antibiot. 1982, 35 (4), 401-410.

100. Deng, Y.; Su, M.; Kang, D.; Liu, X.; Wen, Z.; Li, Y.; Qiu, L.; Shen, B.; Duan, Y.; Huang, Y., Semisynthesis of Platensimycin Derivatives with Antibiotic Activities in Mice via Suzuki-Miyaura Cross-Coupling Reactions. J. Med. Chem. 2018, 61 (24), 11341-11348.

101. Martens, E.; Demain, A. L., Platensimycin and platencin: promising antibiotics for future application in human medicine. J. Antibiot. 2011, 64 (11), 705-710.

102. Jayasuriya, H.; Herath, K. B.; Zhang, C.; Zink, D. L.; Basilio, A.; Genilloud, O.; Diez, M. T.; Vicente, F.; Gonzalez, I.; Salazar, O.; Pelaez, F.; Cummings, R.; Ha, S.; Wang, J.; Singh, S. B., Isolation and structure of platencin: a FabH and FabF dual inhibitor with potent broad-spectrum antibiotic activity. Angew. Chem. 2007, 46 (25), 4684-4688. 
103. Tadano, K.-i., 2.17 Selected diastereoselective reactions: intramolecular diels-alder reactions. In Comprehensive Chirality, Carreira, E. M.; Yamamoto, H., Eds. Elsevier: Amsterdam, 2012; pp 504-524.

104. Ghosh, A. K.; Xi, K., Total synthesis of (-)-platensimycin, a novel antibacterial agent. J. Org. Chem. 2009, 74 (3), 1163-1170.

105. Manallack, D. T.; Crosby, I. T.; Khakham, Y.; Capuano, B., Platensimycin: a promising antimicrobial targeting fatty acid synthesis. Curr. Med. Chem. 2008, 15 (7), 705710.

106. Fair, R. J.; Tor, Y., Antibiotics and bacterial resistance in the 21 st century. Perspect. Medicin. Chem. 2014, 6, PMC.S14459.

107. Joo, S. H., Lipid A as a drug target and therapeutic molecule. Biomol. Ther. 2015, 23 (6), 510-516.

108. Hernick, M.; Fierke, C. A., A method to assay inhibitors of lipopolysaccharide synthesis. Methods Mol. Med. 2008, 142, 143-154.

109. Lee, C.-J.; Liang, X.; Chen, X.; Zeng, D.; Joo, S. H.; Chung, H. S.; Barb, A. W.; Swanson, S. M.; Nicholas, R. A.; Li, Y.; Toone, E. J.; Raetz, C. R. H.; Zhou, P., Speciesspecific and inhibitor-dependent conformations of LpxC: implications for antibiotic design. Chem. Biol. 2011, 18 (1), 38-47.

110. Löppenberg, M.; Müller, H.; Pulina, C.; Oddo, A.; Teese, M.; Jose, J.; Holl, R., Synthesis and biological evaluation of flexible and conformationally constrained LpxC inhibitors. Org. Biomol. Chem. 2013, 11 (36), 6056-6070.

111. Wang, X.; Quinn, P. J.; Yan, A., Kdo2 -lipid A: structural diversity and impact on immunopharmacology. Biol. Rev. Camb. Philos. Soc. 2015, 90 (2), 408-427.

112. Cuny, G. D., A new class of UDP-3-O-(R-3-hydroxymyristol)-N-acetylglucosamine deacetylase (LpxC) inhibitors for the treatment of Gram-negative infections: PCT application WO 2008027466. Expert Opin. Ther. Pat. 2009, 19 (6), 893-899. 
113. Pratap, S.; Kesari, P.; Yadav, R.; Dev, A.; Narwal, M.; Kumar, P., Acyl chain preference and inhibitor identification of Moraxella catarrhalis LpxA: Insight through crystal structure and computational studies. Int. J. Biol. Macromol. 2017, 96, 759-765.

114. Raetz, C. R.; Roderick, S. L., A left-handed parallel beta helix in the structure of UDPN-acetylglucosamine acyltransferase. Science 1995, 270 (5238), 997-1000.

115. Smith, E. W.; Zhang, X.; Behzadi, C.; Andrews, L. D.; Cohen, F.; Chen, Y., Structures of Pseudomonas aeruginosa LpxA reveal the basis for its substrate selectivity. Biochemistry 2015, 54 (38), 5937-5948.

116. Shapiro, A. B.; Ross, P. L.; Gao, N.; Livchak, S.; Kern, G.; Yang, W.; Andrews, B.; Thresher, J., A high-throughput-compatible fluorescence anisotropy-based assay for competitive inhibitors of Escherichia coli UDP-N-acetylglucosamine acyltransferase (LpxA). J. Biomol. Screen. 2013, 18 (3), 341-347.

117. Langridge, G. C.; Phan, M. D.; Turner, D. J.; Perkins, T. T.; Parts, L.; Haase, J.; Charles, I.; Maskell, D. J.; Peters, S. E.; Dougan, G.; Wain, J.; Parkhill, J.; Turner, A. K., Simultaneous assay of every Salmonella typhi gene using one million transposon mutants. Genome Res. 2009, 19 (12), 2308-16.

118. Kroeck, K. G.; Sacco, M. D.; Smith, E. W.; Zhang, X.; Shoun, D.; Akhtar, A.; Darch, S. E.; Cohen, F.; Andrews, L. D.; Knox, J. E.; Chen, Y., Discovery of dual-activity smallmolecule ligands of Pseudomonas aeruginosa LpxA and LpxD using SPR and X-ray crystallography. Sci. Rep. 2019, 9 (1), 15450.

119. Han, W.; Ma, X.; Balibar, C. J.; Baxter Rath, C. M.; Benton, B.; Bermingham, A.; Casey, F.; Chie-Leon, B.; Cho, M.-K.; Frank, A. O.; Frommlet, A.; Ho, C.-M.; Lee, P. S.; Li, M.; Lingel, A.; Ma, S.; Merritt, H.; Ornelas, E.; De Pascale, G.; Prathapam, R.; Prosen, K. R.; Rasper, D.; Ruzin, A.; Sawyer, W. S.; Shaul, J.; Shen, X.; Shia, S.; Steffek, M.; Subramanian, S.; Vo, J.; Wang, F.; Wartchow, C.; Uehara, T., Two distinct mechanisms of inhibition of 
LpxA acyltransferase essential for lipopolysaccharide biosynthesis. J. Am. Chem. Soc. 2020, $142(9), 4445-4455$.

120. Jenkins, R. J.; Heslip, K. A.; Meagher, J. L.; Stuckey, J. A.; Dotson, G. D., Structural basis for the recognition of peptide RJPXD33 by acyltransferases in lipid a biosynthesis. $J$. Biol. Chem. 2014, 289 (22), 15527-15535.

121. Williams, A. H.; Immormino, R. M.; Gewirth, D. T.; Raetz, C. R. H., Structure of UDP-N-acetylglucosamine acyltransferase with a bound antibacterial pentadecapeptide. Proc. Natl. Acad. Sci. U. S. A. 2006, 103 (29), 10877-10882.

122. Zhou, P.; Zhao, J., Structure, inhibition, and regulation of essential lipid A enzymes. Biochim. Biophys. acta. Mol. Cell. Biol. Lip. 2017, 1862 (11), 1424-1438.

123. Benson, R. E.; Gottlin, E. B.; Christensen, D. J.; Hamilton, P. T., Intracellular expression of peptide fusions for demonstration of protein essentiality in bacteria. Antimicrob. Agents Chemother. 2003, 47 (9), 2875-2881.

124. Dangkulwanich, M.; Raetz, C. R. H.; Williams, A. H.; Dangkulwanich, M.; Williams, A. H., Structure guided design of an antibacterial peptide that targets UDP-Nacetylglucosamine acyltransferase. Sci. Rep. 2019, 9 (1), 3947.

125. Jenkins, R. J.; Dotson, G. D., Dual Targeting antibacterial peptide inhibitor of early lipid a biosynthesis. ACS Chem. Biol. 2012, 7 (7), 1170-1177.

126. Bhaskar, B. V.; Zheng, G. Y.; Gu, W.; Babu, T. M. C.; Rammohan, A.; Zyryanov, G. V., Structure-based virtual screening of Pseudomonas aeruginosa LpxA inhibitors using pharmacophore-based approach. Biomolecules 2020, 10 (2).

127. Ma, X.; Prathapam, R.; Wartchow, C.; Chie-Leon, B.; Ho, C.-M.; De Vicente, J.; Han, W.; Li, M.; Lu, Y.; Ramurthy, S.; Shia, S.; Steffek, M.; Uehara, T., Structural and biological basis of small molecule inhibition of Escherichia coli LpxD acyltransferase essential for lipopolysaccharide biosynthesis. ACS Infect. Dis. 2020, 6 (6), 1480-1489. 
128. Bohl, T. E.; Aihara, H., Current progress in the structural and biochemical characterization of proteins involved in the assembly of lipopolysaccharide. Int. J. Microbiol. 2018, 32, 6-155.

129. Jana, S. K.; Löppenberg, M.; Daniliuc, C. G.; Holl, R., C-Triazolyl $\beta$-d-furanosides as LpxC inhibitors: stereoselective synthesis and biological evaluation. Tetrahedron 2014, 70 (37), 6569-6577.

130. Stokes, S. S.; Morningstar, M.; Kocis, H.; Verheijen, J. C., New antibacterial agents: patent applications published in 2010. Pharm. Pat. Anal. 2012, 1 (5), 601-620.

131. Surivet, J.-P.; Panchaud, P.; Specklin, J.-L.; Diethelm, S.; Blumstein, A.-C.; Gauvin, J.-C.; Jacob, L.; Masse, F.; Mathieu, G.; Mirre, A.; Schmitt, C.; Lange, R.; Tidten-Luksch, N.; Gnerre, C.; Seeland, S.; Herrmann, C.; Seiler, P.; Enderlin-Paput, M.; Mac Sweeney, A.; Wicki, M.; Hubschwerlen, C.; Ritz, D.; Rueedi, G., Discovery of novel inhibitors of Lpxc displaying potent in vitro activity against Gram-negative bacteria. J. Med. Chem. 2020, 63 (1), 66-87.

132. Barb, A. W.; Zhou, P., Mechanism and inhibition of LpxC: an essential zincdependent deacetylase of bacterial lipid A synthesis. Curr. Pharm. Biotechnol. 2008, 9 (1), 915.

133. Clements, J. M.; Coignard, F.; Johnson, I.; Chandler, S.; Palan, S.; Waller, A.; Wijkmans, J.; Hunter, M. G., Antibacterial activities and characterization of novel inhibitors of LpxC. Antimicrob. Agents Chemother. 2002, 46 (6), 1793-1799.

134. Kalinin, D. V.; Holl, R., LpxC inhibitors: a patent review (2010-2016). Expert Opin. Ther. Pat. 2017, 27 (11), 1227-1250.

135. Kalinin, D. V.; Holl, R., Insights into the zinc-dependent deacetylase Lpxc: biochemical properties and inhibitor design. Curr. Top. Med. Chem. 2016, 16 (21), 23792430. 
136. Liu, F.; Ma, S., Recent process in the inhibitors of udp-3-o-(r-3-hydroxyacyl)nacetylglucosamine deacetylase (Lpxc) against Gram-negative bacteria. Mini Rev. Med. Chem. 2018, 18 (4), 310-323.

137. Erwin, A. L., Antibacterial drug discovery targeting the lipopolysaccharide biosynthetic enzyme LpxC. Cold Spring Harb. Perspect. Med. 2016, 6 (7), a025304.

138. Onishi, H. R.; Pelak, B. A.; Gerckens, L. S.; Silver, L. L.; Kahan, F. M.; Chen, M.-H.; Patchett, A. A.; Galloway, S. M.; Hyland, S. A.; Anderson, M. S.; Raetz, C. R. H., Antibacterial Agents That Inhibit Lipid A Biosynthesis. Science 1996, 274 (5289), 980-982.

139. Liang, X.; Lee, C.-J.; Zhao, J.; Toone, E. J.; Zhou, P., Synthesis, structure, and antibiotic activity of aryl-substituted LpxC inhibitors. J. Med. Chem. 2013, 56 (17), 69546966.

140. Liang, X.; Lee, C.-J.; Chen, X.; Chung, H. S.; Zeng, D.; Raetz, C. R. H.; Li, Y.; Zhou, P.; Toone, E. J., Syntheses, structures and antibiotic activities of LpxC inhibitors based on the diacetylene scaffold. Biorg. Med. Chem. 2011, 19 (2), 852-860.

141. Mdluli, K. E.; Witte, P. R.; Kline, T.; Barb, A. W.; Erwin, A. L.; Mansfield, B. E.; McClerren, A. L.; Pirrung, M. C.; Tumey, L. N.; Warrener, P.; Raetz, C. R. H.; Stover, C. K., Molecular validation of $\mathrm{LpxC}$ as an antibacterial drug target in Pseudomonas aeruginosa. Antimicrob. Agents Chemother. 2006, 50 (6), 2178-2184.

142. Chen, M.-H.; Steiner, M. G.; de Laszlo, S. E.; Patchett, A. A.; Anderson, M. S.; Hyland, S. A.; Russell Onishi, H.; Silyer, L. L.; Raetz, C. R. H., Carbohydroxamidooxazolidines: antibacterial agents that target lipid A biosynthesis. Bioorg. Med. Chem. Lett. 1999, 9 (3), 313-318.

143. Jackman, J. E.; Fierke, C. A.; Tumey, L. N.; Pirrung, M.; Uchiyama, T.; Tahir, S. H.; Hindsgaul, O.; Raetz, C. R., Antibacterial agents that target lipid A biosynthesis in gramnegative bacteria. Inhibition of diverse UDP-3-O-(r-3-hydroxymyristoyl)-n- 
acetylglucosamine deacetylases by substrate analogs containing zinc binding motifs. J. Biol. Chem. 2000, 275 (15), 11002-11009.

144. Coggins, B. E.; McClerren, A. L.; Jiang, L.; Li, X.; Rudolph, J.; Hindsgaul, O.; Raetz, C. R. H.; Zhou, P., Refined solution structure of the LpxC-TU-514 complex and pKa analysis of an active site histidine: insights into the mechanism and inhibitor design. Biochemistry 2005, 44 (4), 1114-1126.

145. Coggins, B. E.; Li, X.; McClerren, A. L.; Hindsgaul, O.; Raetz, C. R. H.; Zhou, P., Stucture of the LpxC deacetylase with a bound substrate-analog inhibitor. Nat. Struct. Biol. 2003, $10(8), 645-651$.

146. McClerren, A. L.; Endsley, S.; Bowman, J. L.; Andersen, N. H.; Guan, Z.; Rudolph, J.; Raetz, C. R. H., A slow, tight-binding inhibitor of the zinc-dependent deacetylase LpxC of lipid A biosynthesis with antibiotic activity comparable to ciprofloxacin. Biochemistry 2005, 44 (50), 16574-16583.

147. Barb, A. W.; Jiang, L.; Raetz, C. R. H.; Zhou, P., Structure of the deacetylase LpxC bound to the antibiotic CHIR-090: Time-dependent inhibition and specificity in ligand binding. Proc. Natl. Acad. Sci. U. S. A. 2007, 104 (47), 18433-18438.

148. Barb, A. W.; McClerren, A. L.; Snehelatha, K.; Reynolds, C. M.; Zhou, P.; Raetz, C. R. H., Inhibition of lipid A biosynthesis as the primary mechanism of CHIR-090 antibiotic activity in Escherichia coli. Biochemistry 2007, 46 (12), 3793-3802.

149. Tan, J. H.; Vidaillac, C.; Yam, J. K. H.; Chua, S. L.; Givskov, M.; Yang, L., In Vitro and In Vivo Efficacy of an LpxC inhibitor, CHIR-090, alone or combined with colistin against Pseudomonas aeruginosa biofilm. Antimicrob. Agents Chemother. 2017, 61 (7), e02223-16.

150. Caughlan, R. E.; Jones, A. K.; DeLucia, A. M.; Woods, A. L.; Xie, L.; Ma, B.; Barnes, S. W.; Walker, J. R.; Sprague, E. R.; Yang, X.; Dean, C. R., Mechanisms decreasing in vitro 
susceptibility to the LpxC inhibitor CHIR-090 in the Gram-negative pathogen Pseudomonas aeruginosa. Antimicrob. Agents Chemother. 2012, 56 (1), 17-27.

151. Lee, C.-R.; Lee, J. H.; Jeong, B. C.; Lee, S. H., Lipid a biosynthesis of multidrugresistant pathogens - a novel drug target. Curr. Pharm. Des. 2013, 19 (36), 6534-6550.

152. Mochalkin, I.; Knafels, J. D.; Lightle, S., Crystal structure of LpxC from Pseudomonas aeruginosa complexed with the potent BB-78485 inhibitor. Protein Sci. 2008, 17 (3), 450-457.

153. Ding, S.; Dai, R.-Y.; Wang, W.-K.; Cao, Q.; Lan, L.-F.; Zhou, X.-L.; Yang, Y.-S., Design, synthesis and structure-activity relationship evaluation of novel LpxC inhibitors as Gram-negative antibacterial agents. Bioorg. Med. Chem. Lett. 2018, 28 (2), 94-102.

154. Cohen, F.; Aggen, J. B.; Andrews, L. D.; Assar, Z.; Boggs, J.; Choi, T.; Dozzo, P.; Easterday, A. N.; Haglund, C. M.; Hildebrandt, D. J.; Holt, M. C.; Joly, K.; Jubb, A.; Kamal, Z.; Kane, T. R.; Konradi, A. W.; Krause, K. M.; Linsell, M. S.; Machajewski, T. D.; Miroshnikova, O.; Moser, H. E.; Nieto, V.; Phan, T.; Plato, C.; Serio, A. W.; Seroogy, J.; Shakhmin, A.; Stein, A. J.; Sun, A. D.; Sviridov, S.; Wang, Z.; Wlasichuk, K.; Yang, W.; Zhou, X.; Zhu, H.; Cirz, R. T., Optimization of LpxC inhibitors for antibacterial activity and cardiovascular safety. ChemMedChem 2019, 14 (16), 1560-1572.

155. Krause, K. M.; Haglund, C. M.; Hebner, C.; Serio, A. W.; Lee, G.; Nieto, V.; Cohen, F.; Kane, T. R.; Machajewski, T. D.; Hildebrandt, D.; Pillar, C.; Thwaites, M.; Hall, D.; Miesel, L.; Hackel, M.; Burek, A.; Andrews, L. D.; Armstrong, E.; Swem, L.; Jubb, A.; Cirz, R. T., Potent LpxC inhibitors with in vitro activity against multidrug-resistant Pseudomonas aeruginosa. Antimicrob. Agents Chemother. 2019, 63 (11).

156. Jenkins, R. J.; Meagher, J.; Stuckey, J. A.; Dotson, G. D. In Probing early acyltransferases of lipid A with inhibitory peptides, American Chemical Society: 2012; pp BIOL-152. 
157. Williams, A. H.; Raetz, C. R. H., Structural basis for the acyl chain selectivity and mechanism of UDP-N-acetylglucosamine acyltransferase. Proc. Natl. Acad. Sci. U. S. A. 2007, 104 (34), 13543-13550.

158. Badger, J.; Chie-Leon, B.; Logan, C.; Sridhar, V.; Sankaran, B.; Zwart, P. H.; Nienaber, V., The structure of LpxD from Pseudomonas aeruginosa at $1.3 \AA$ A resolution. Acta Crystallogr Sect F Struct Biol Cryst Commun 2011, 67 (Pt 7), 749-52.

159. Jenkins, R. J.; Dotson, G. D. In Identification of a bifunctional inhibitory probe targeting early acyltransferases of Lipid A biosynthesis, American Chemical Society: 2011; pp BIOL-63.

160. Dotson, G. D.; Jenkins, R. J. In Dual inhibition of early acyltransferases in Eschericia coli lipid A biosynthesis, American Chemical Society: 2012; pp BIOL-216.

161. Ma, X.; Prathapam, R.; Wartchow, C.; Chie-Leon, B.; Ho, C.-M.; De, V. J.; Han, W.; Li, M.; Lu, Y.; Ramurthy, S.; Shia, S.; Steffek, M.; Uehara, T., Structural and biological basis of small molecule inhibition of Escherichia coli LpxD acyltransferase essential for lipopolysaccharide biosynthesis. ACS Infect. Dis. 2020, 6 (6), 1480-1489.

162. Rath, S. N.; Ray, M.; Pattnaik, A.; Pradhan, S. K., Drug target identification and elucidation of natural inhibitors for Bordetella petrii: An in silico study. Genomics Inform. 2016, 14 (4), 241-254.

163. Metzger, L. E. t.; Raetz, C. R. H., An alternative route for UDP-diacylglucosamine hydrolysis in bacterial lipid A biosynthesis. Biochemistry 2010, 49 (31), 6715-26.

164. Cho, J.; Lee, C.-J.; Zhao, J.; Young, H. E.; Zhou, P., Structure of the essential Haemophilus influenzae UDP-diacylglucosamine pyrophosphohydrolase LpxH in lipid A biosynthesis. Nat. Microbiol. 2016, 1 (11), 16154.

165. Okada, C.; Wakabayashi, H.; Kobayashi, M.; Shinoda, A.; Tanaka, I.; Yao, M., Crystal structures of the UDP-diacylglucosamine pyrophosphohydrase LpxH from Pseudomonas aeruginosa. Sci. Rep. 2016, 6, 32822. 
166. Richie, D. L.; Takeoka, K. T.; Bojkovic, J.; Metzger, L. E. I. V.; Rath, C. M.; Sawyer, W. S.; Wei, J.-R.; Dean, C. R., Toxic accumulation of LPS pathway intermediates underlies the requirement of LpxH for growth of Acinetobacter baumannii ATCC 19606. PLoS One 2016, 11 (8), e0160918/1-e0160918/22.

167. Nayar, A. S.; Dougherty, T. J.; Ferguson, K. E.; Miller, A. A.; McLeod, S. M.; Granger, B. A.; Brown, D. G.; McWilliams, L.; Stacey, C.; Leach, L. J.; Narita, S.-I.; Tokuda, H., Novel antibacterial targets and compounds revealed by a high-throughput cell wall reporter assay. J. Bacteriol. 2015, 197 (10), 1726-34.

168. Lee, M.; Zhao, J.; Kwak, S.-H.; Cho, J.; Lee, M.; Gillespie, R. A.; Kwon, D.-Y.; Lee, H.; Park, H.-J.; Wu, Q.; Zhou, P.; Hong, J., Structure-activity relationship of sulfonyl piperazine LpxH inhibitors analyzed by an LpxE-coupled malachite green assay. ACS Infect. Dis. 2019, 5 (4), 641-651.

169. Cho, J.; Fenton, B. A.; Zhao, J.; Zhou, P.; Lee, M.; Cochrane, C. S.; Webster, C. G.; Hong, J.; Zhou, P., Structural basis of the UDP-diacylglucosamine pyrophosphohydrolase LpxH inhibition by sulfonyl piperazine antibiotics. Proc. Natl. Acad. Sci. U S A 2020, 117 (8), 4109-4116.

170. Kwak, S.-H.; Cochrane, C. S.; Ennis, A. F.; Lim, W. Y.; Webster, C. G.; Cho, J.; Fenton, B. A.; Zhou, P.; Hong, J., Synthesis and evaluation of sulfonyl piperazine LpxH inhibitors. Bioorg. Chem. 2020, 102 (104055).

171. Bohl, T. E.; Lee, J. K.; Shi, K.; Kurahashi, K.; Aihara, H.; Ieong, P.; Amaro, R. E.; Lee, T.; Kankanala, J.; Wang, Z.; Demir, O.; Amaro, R. E., The substrate-binding cap of the UDP-diacylglucosamine pyrophosphatase $\mathrm{LpxH}$ is highly flexible, enabling facile substrate binding and product release. J. Biol. Chem. 2018, 293 (21), 7969-7981.

172. Kwak, S.-H.; Cochrane, C. S.; Ennis, A. F.; Lim, W. Y.; Webster, C. G.; Cho, J.; Fenton, B. A.; Zhou, P.; Hong, J., Synthesis and evaluation of sulfonyl piperazine LpxH inhibitors. Bioorg. Chem. 2020, 102, 104055. 
173. Robinson, J. A., Folded synthetic peptides and other molecules targeting outer membrane protein complexes in Gram-negative bacteria. Front. Chem. 2019, 7 (45), 1-11.

174. Luther, A.; Urfer, M.; Zahn, M.; Müller, M.; Wang, S. Y.; Mondal, M.; Vitale, A.; Hartmann, J. B.; Sharpe, T.; Monte, F. L.; Kocherla, H.; Cline, E.; Pessi, G.; Rath, P.; Modaresi, S. M.; Chiquet, P.; Stiegeler, S.; Verbree, C.; Remus, T.; Schmitt, M.; Kolopp, C.; Westwood, M. A.; Desjonquères, N.; Brabet, E.; Hell, S.; LePoupon, K.; Vermeulen, A.; Jaisson, R.; Rithié, V.; Upert, G.; Lederer, A.; Zbinden, P.; Wach, A.; Moehle, K.; Zerbe, K.; Locher, H. H.; Bernardini, F.; Dale , G. E.; Eberll, L.; Wollscheid, B.; Hiller, S.; Robinson, J. A.; Obrecht , D., Chimeric peptidomimetic antibiotics against Gram-negative bacteria. Nature 2019, 576, 452-458.

175. Sousa, M. C., New antibiotics target the outer membrane of bacteria. Nature 2019, $576,389-390$.

176. Parsons, J. B.; Yao, J.; Frank, M. W.; Rock, C. O., FabH mutations confer resistance to FabF-directed antibiotics in Staphylococcus aureus. Antimicrob. Agents Chemother. 2015, $59(2), 849-858$.

177. Liu, X.; Wang, Z.; Feng, X.; Bai, E.; Xiong, Y.; Zhu, X.; Shen, B.; Duan, Y.; Huang, Y., Platensimycin-encapsulated poly(lactic-co-glycolic acid) and poly(amidoamine) dendrimers nanoparticles with enhanced anti-staphylococcal activity in vivo. Bioconjugate Chem. 2020, 31 (5), 1425-1437.

178. Tomaras, A. P.; McPherson, C. J.; Kuhn, M.; Carifa, A.; Mullins, L.; George, D.; Desbonnet, C.; Eidem, T. M.; Montgomery, J. I.; Brown, M. F.; Reilly, U.; Miller, A. A.; O’Donnell, J. P., LpxC inhibitors as new antibacterial agents and tools for studying regulation of lipid A biosynthesis in Gram-negative pathogens. mBio 2014, 5 (5), e01551-14.

179. Ferrand, A.; Vergalli, J.; Pagès, J. M.; Davin-Regli, A., An intertwined network of regulation controls membrane permeability including drug influx and efflux in Enterobacteriaceae. Microorganisms 2020, 8 (6), 833. 


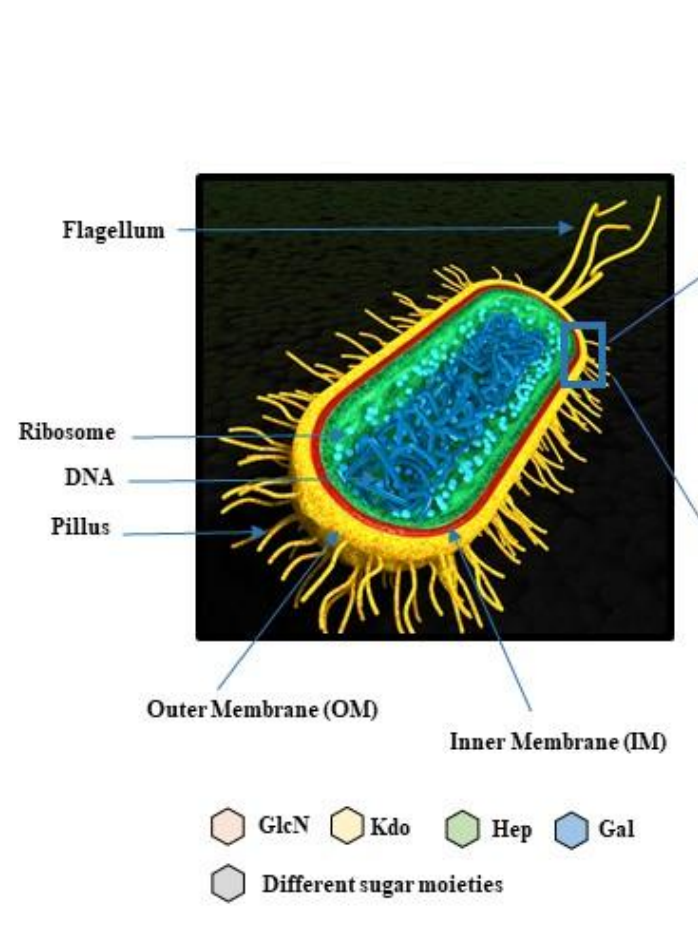

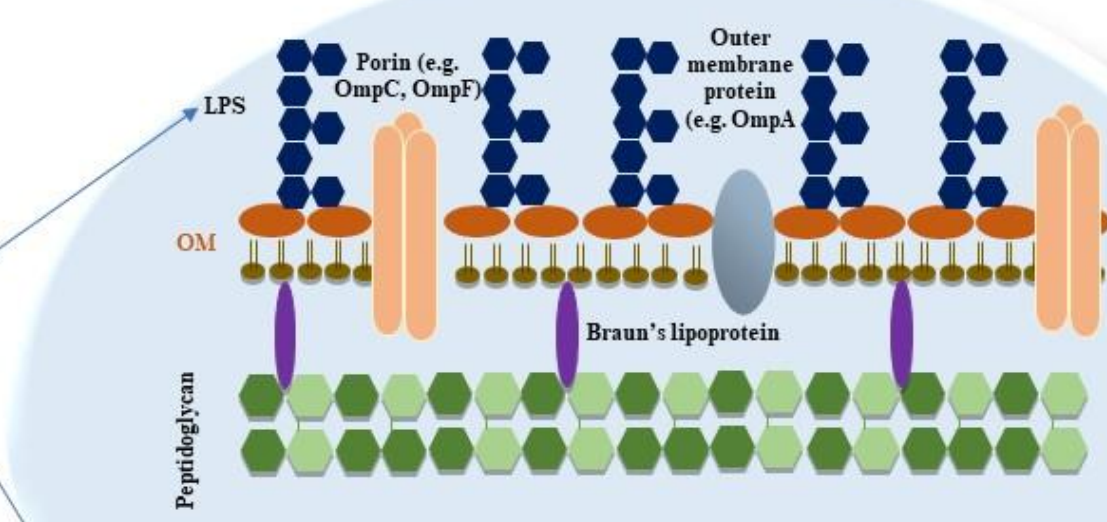

Periplasm

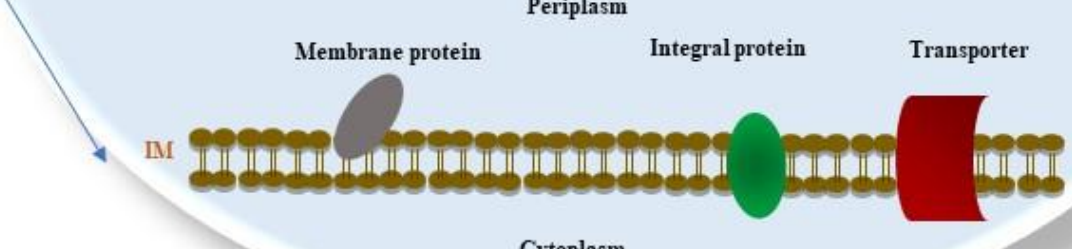

Cytoplasm
C

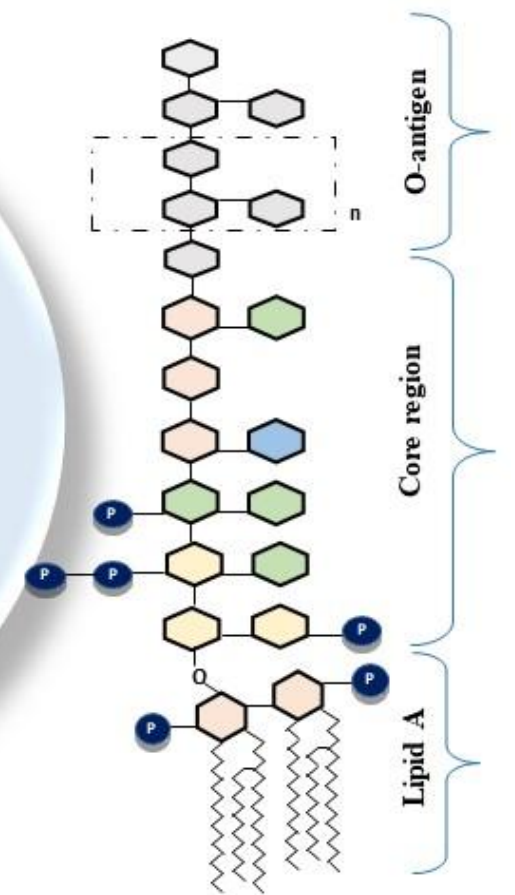

Figure 1 


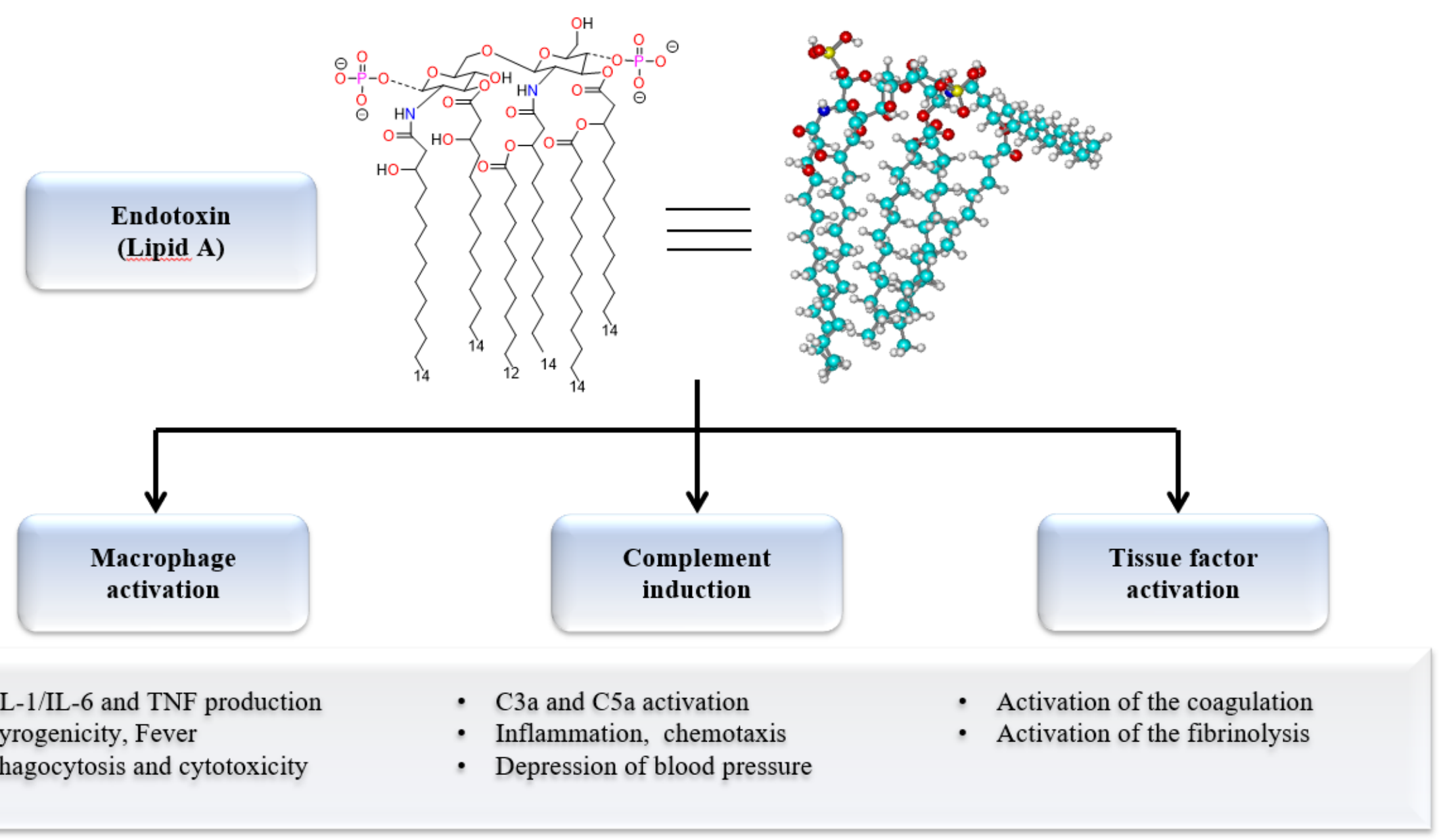

Figure 2 


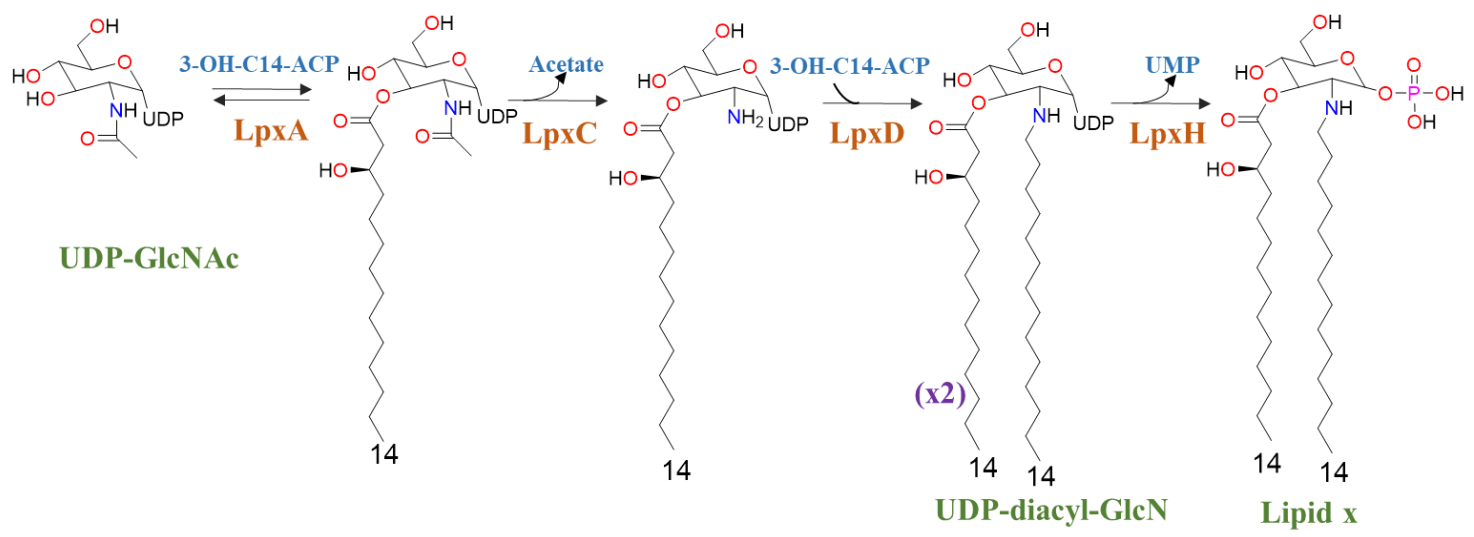

Kdo2-lipid A
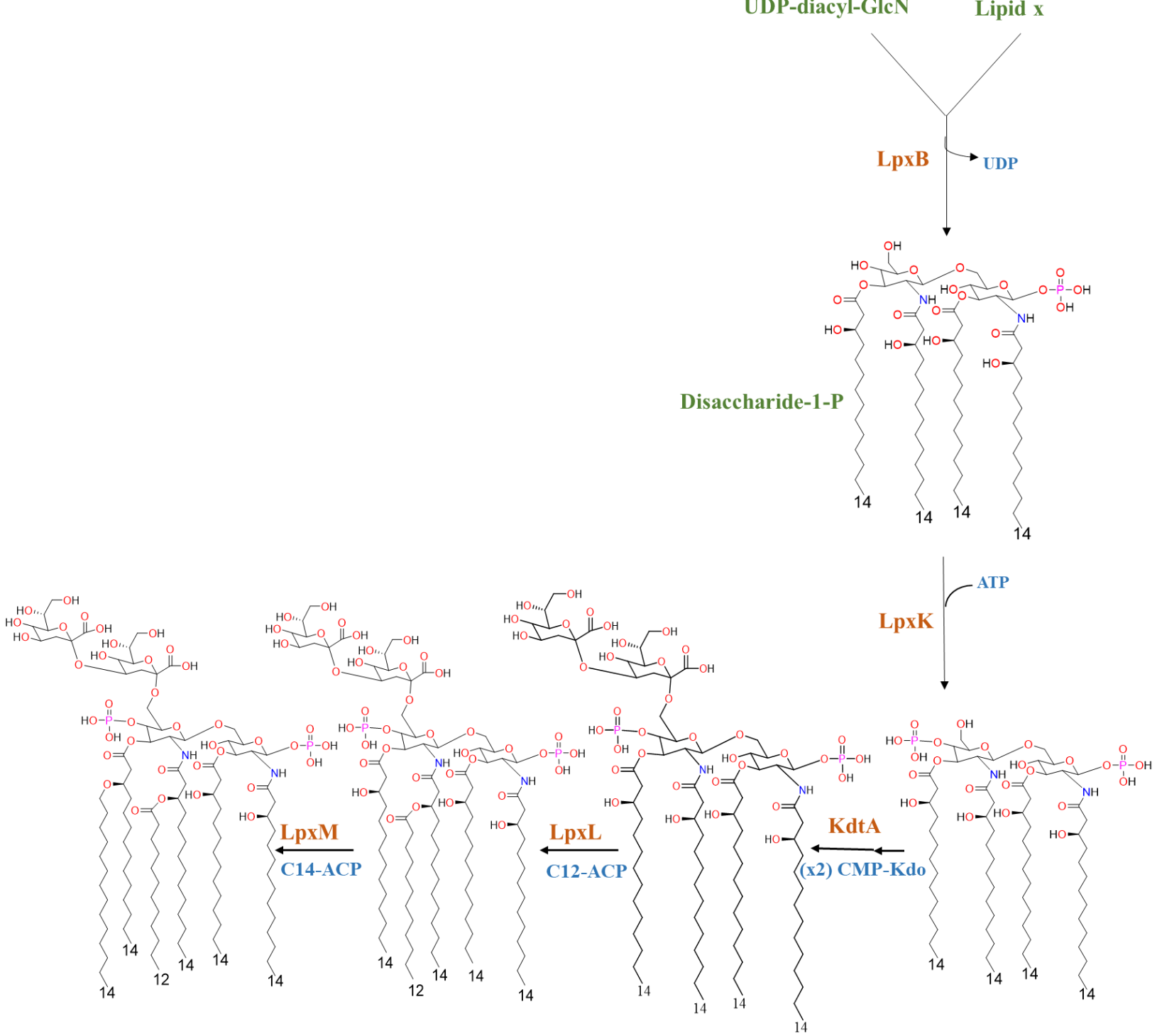

Kdo2-lipid IVA

Lipid IVA

\section{Figure 3}



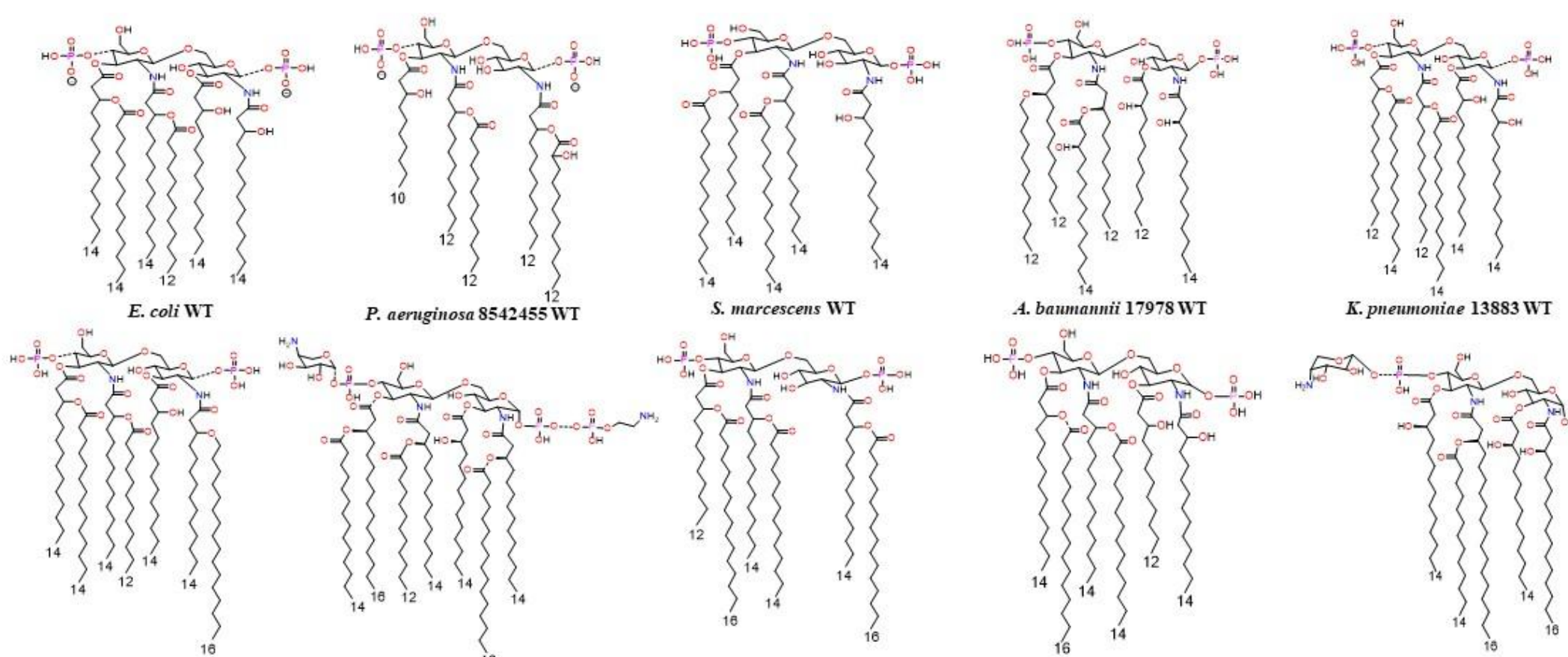

P. aeruginosa $8542455 \mathrm{WT}$
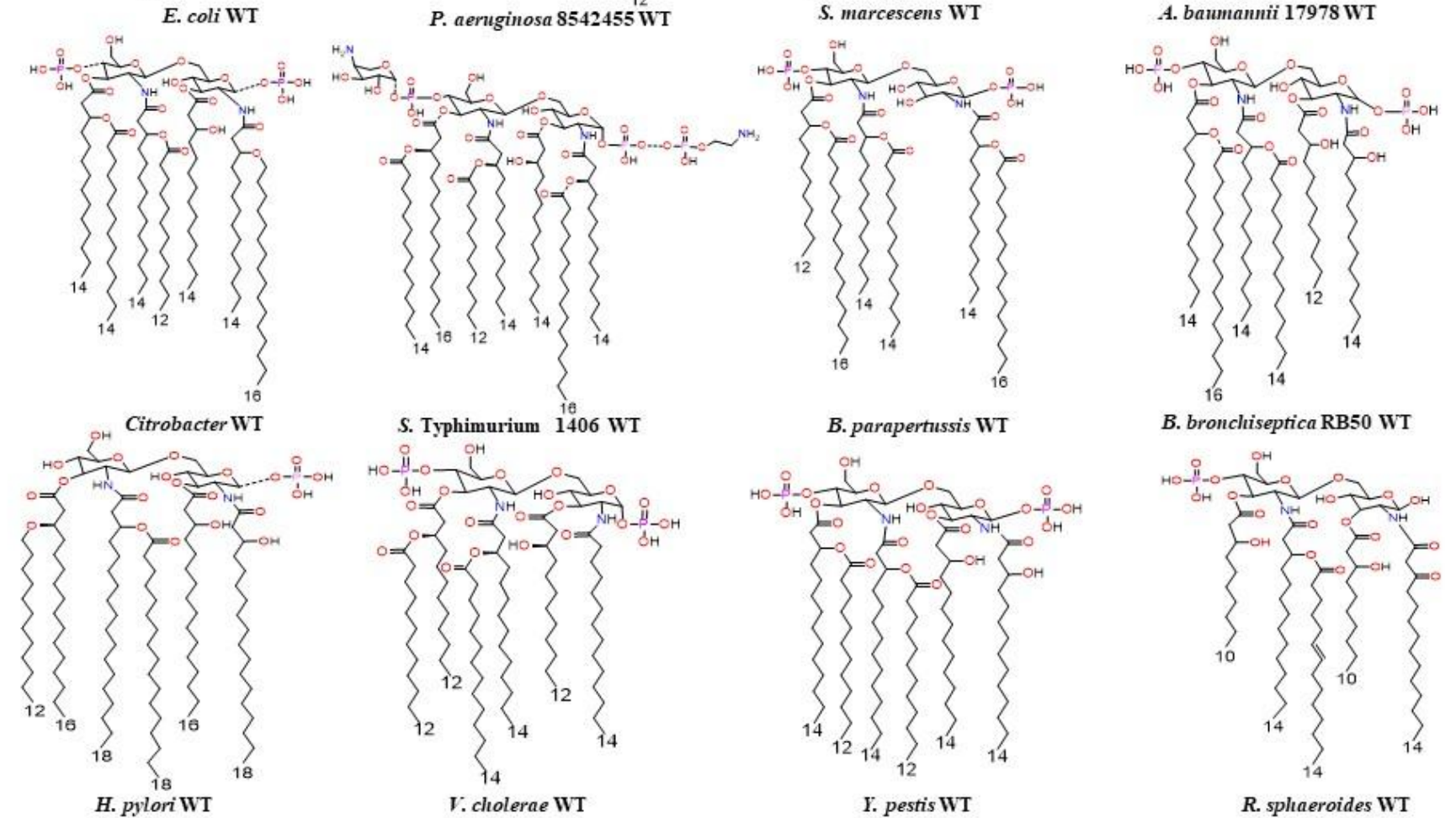

K. pnenmoniae $13883 \mathrm{WT}$
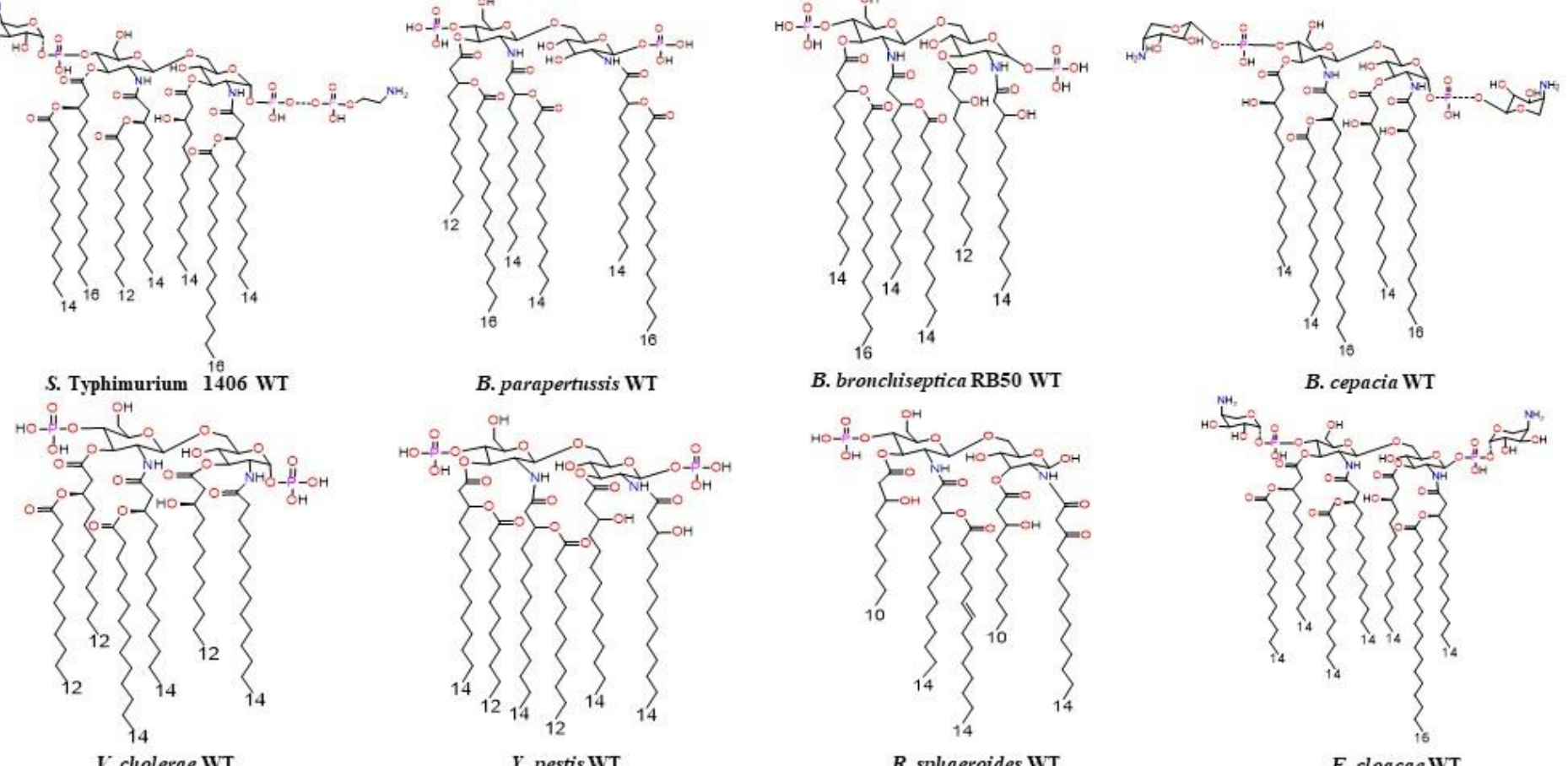
Figure 4

A

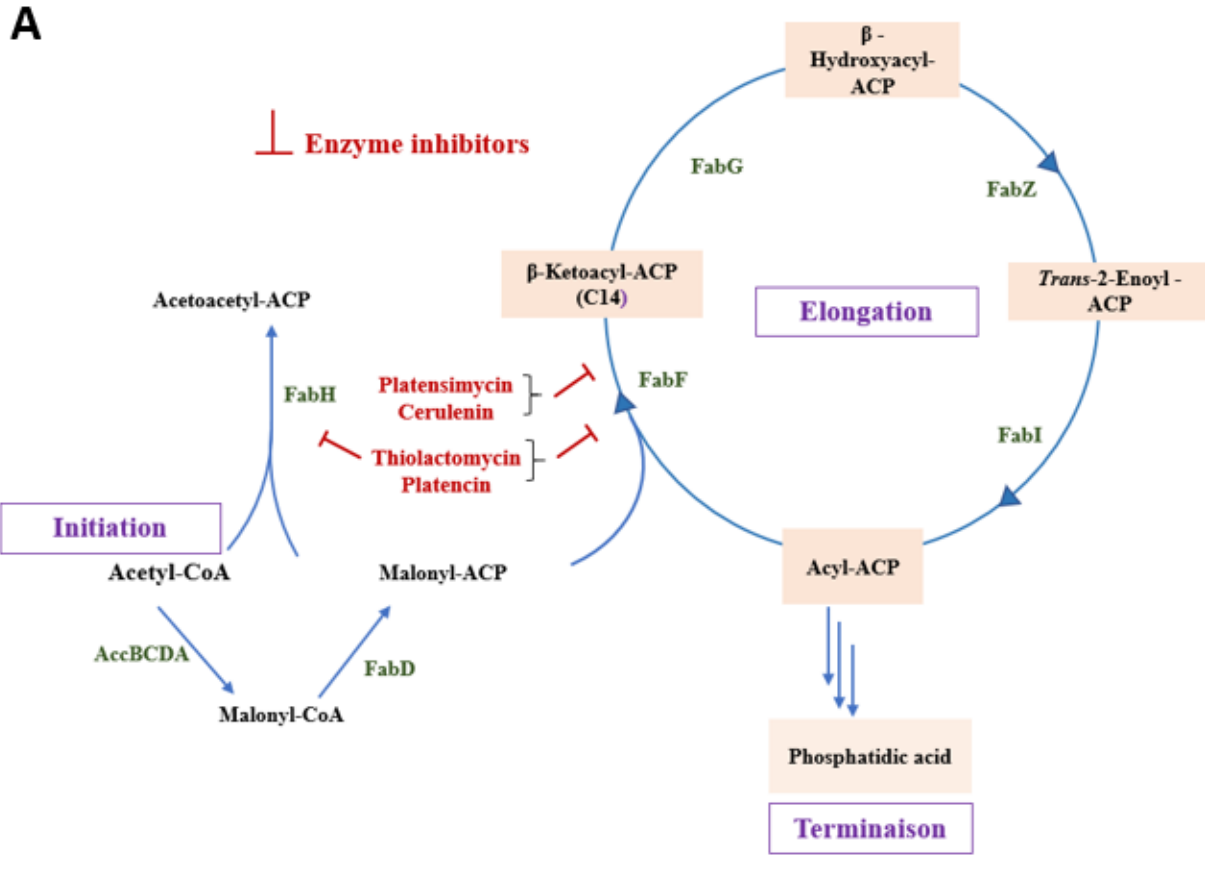

B

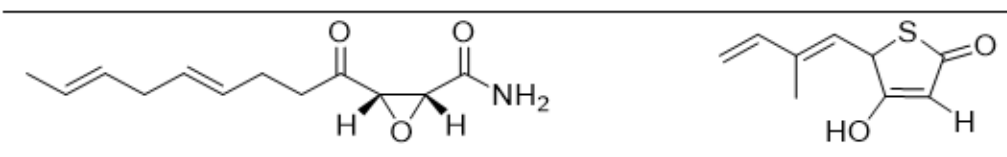

Cerulenin 1

Thiolactomycin 2

IC $_{5_{0}}$ against $\mathrm{FabF} / \mathrm{B}$ inhibitors $=0.1-2 \mu \mathrm{g} / \mathrm{mL} \quad$ IC $_{50}$ against $\mathrm{FabF} / \mathrm{n}$ inhibitor $=20 \mu \mathrm{M}$

IC $_{50}$ against FabHinhibitors $=150 \mu \mathrm{g} / \mathrm{mL} \quad$ IC $_{50}$ against FabH inhibitors $=90 \mu \mathrm{M}$

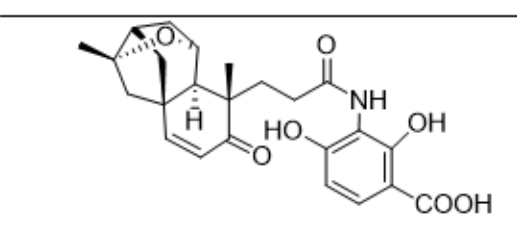

Platensim ycin 3

IC $_{50}$ against $\mathrm{FabF}$ inhibitors $=0.29 \mu \mathrm{M}$ IC 50 of $\mathrm{F}$ abH inhibitors $=247 \mu \mathrm{M}$

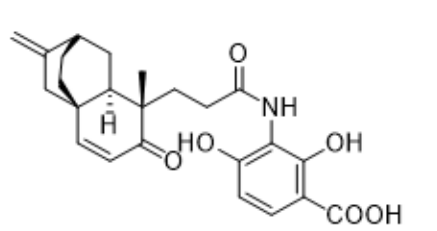

Platencin 4

IC $_{50}$ against $F$ abF inhibitors $=4.58 \mu \mathrm{M}$ IC 50 of FabH inhibitors $=9.17 \mu \mathrm{M}$

Figure 5 


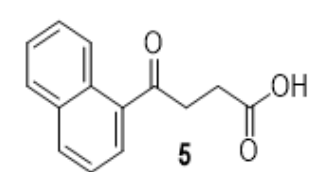

$\mathrm{LpxA} \mathrm{K}_{\mathrm{D}}=\mathrm{ND}$

$\mathrm{L}_{\mathrm{pxD} \mathrm{K}} \mathrm{K}_{\mathrm{D}}=\mathrm{ND}$
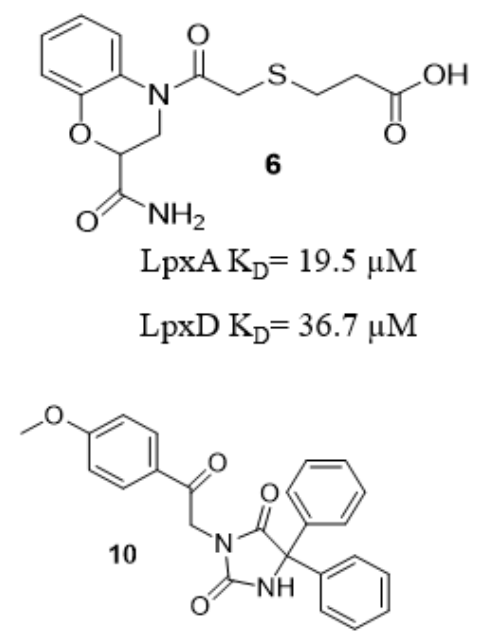

$\mathrm{IC}_{50}=1.4 \mu \mathrm{M}$

$\mathrm{K}_{\mathrm{D}}=0.1 \mu \mathrm{M}$

MIC E.coli ATCC $25922=>16 \mu \mathrm{g} / \mathrm{mL}$ MIC E.coli $\Delta$ tolC $=0.5 \mu \mathrm{g} / \mathrm{mL}$

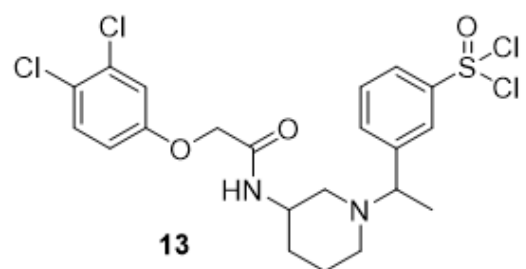

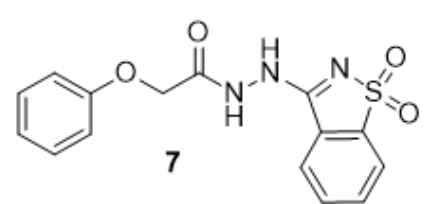

$\mathrm{LpxA} \mathrm{K}_{\mathrm{D}}=16.7 \mu \mathrm{M}$ $\mathrm{L}_{\mathrm{pxD} \mathrm{K}}=\mathrm{ND}$

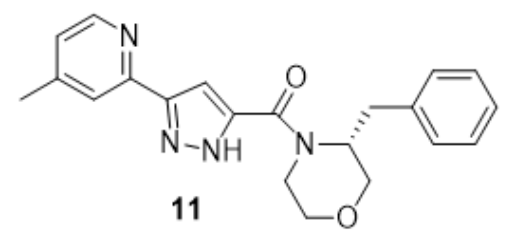

$\mathrm{IC}_{50}=4.8 \mu \mathrm{M}$

$$
\mathrm{K}_{\mathrm{D}}=110 \mu \mathrm{M}
$$

MIC E.coli ATCC 25922=>128 $\mu \mathrm{g} / \mathrm{mL}$

MIC E.coli $\Delta$ tolC $=2 \mu \mathrm{g} / \mathrm{mL}$

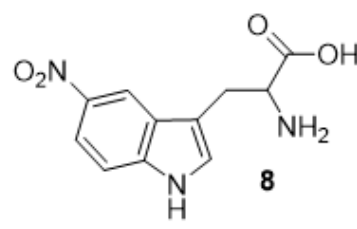

$$
\begin{gathered}
\mathrm{LpxA} \mathrm{K}_{\mathrm{D}}=13.6 \mu \mathrm{M} \\
\mathrm{LpxD} \mathrm{K}_{\mathrm{D}}=\mathrm{ND}
\end{gathered}
$$

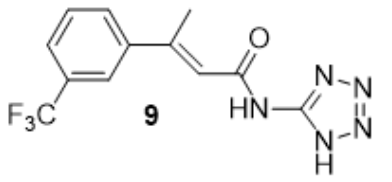

$\mathrm{LpxA} \mathrm{K}_{\mathrm{D}}=2.1 \mu \mathrm{M}$

$\mathrm{L}_{\mathrm{pxD} \mathrm{K}} \mathrm{K}_{\mathrm{D}}=\mathrm{ND}$

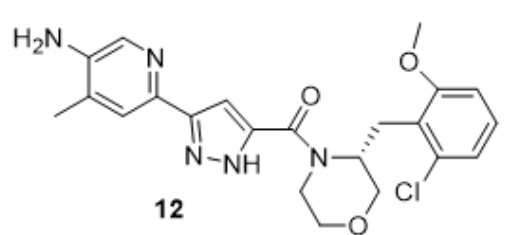

$$
\begin{gathered}
\mathrm{IC}_{50}=0.6 \mu \mathrm{M} \\
\mathrm{K}_{\mathrm{D}}=\mathrm{ND}
\end{gathered}
$$

MIC E.coli ATCC 25922=16 $\mu \mathrm{g} / \mathrm{mL}$ MIC E.coli $\Delta$ tolC $=<0.125 \mu \mathrm{g} / \mathrm{mL}$
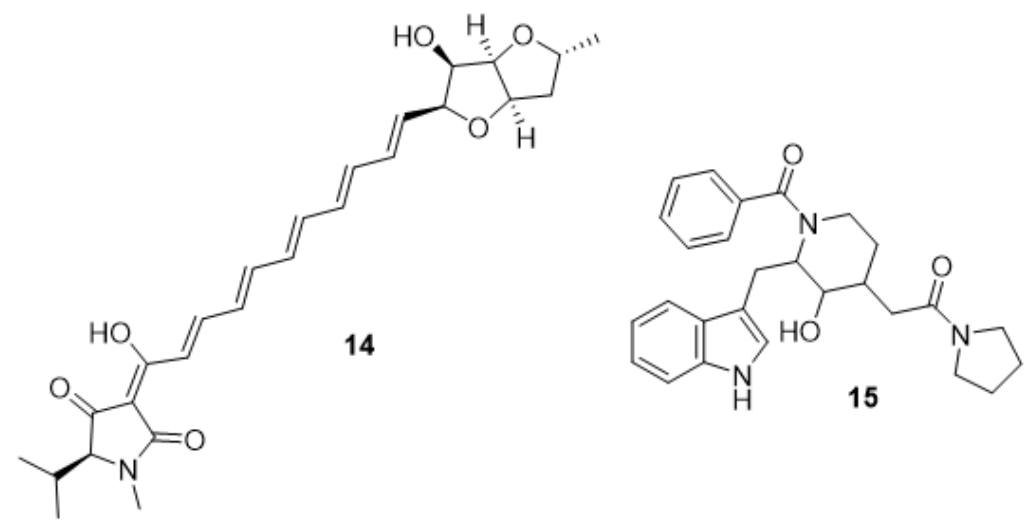

Figure 6 


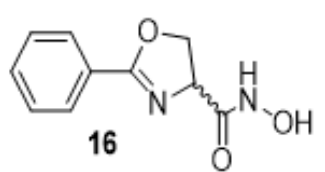

MIC $E$. coli $=200-400 \mu \mathrm{g} / \mathrm{mL}$ $\mathrm{IC}_{50} E$. coli $=8.5 \mu \mathrm{M}$ $\mathrm{K}_{\mathrm{i}}$ E. coli $24 \mu \mathrm{M}$

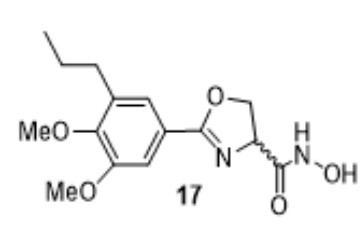

MIC $E$. coli $=1-3 \mu \mathrm{g} / \mathrm{mL}$

MIC $P$. aeruginosa $>100 \mu \mathrm{g} / \mathrm{mL}$

$\mathrm{IC}_{50} E$. coli $=30 \mathrm{nM}$

$\mathrm{K}_{\mathrm{i}}$ E. coli $=50 \mathrm{nM}$

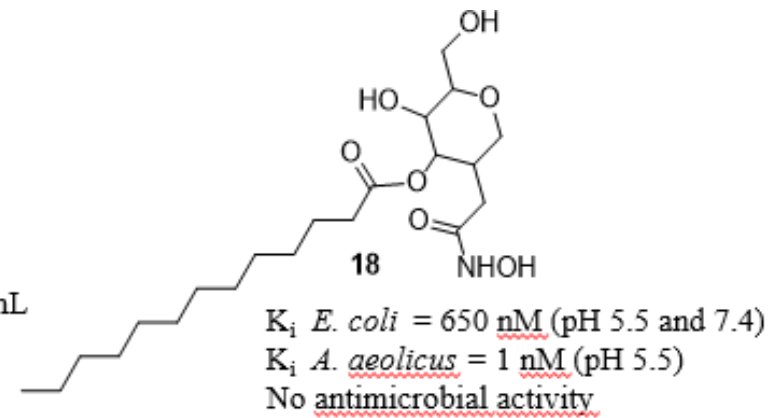

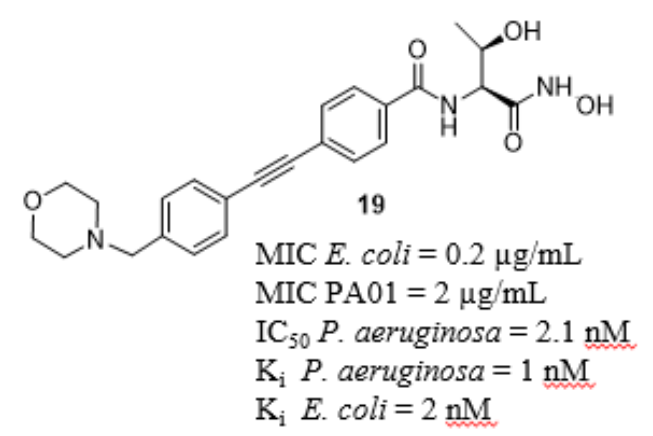

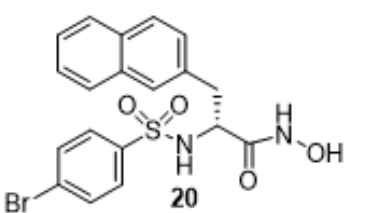

MIC $E$. coli $=2 \mu \mathrm{g} / \mathrm{mL}$

MIC $P$. aeruginosa $>32 \mu \mathrm{g} / \mathrm{mL}$

$\mathrm{IC}_{50} E$. coli $=400 \mathrm{nM}$

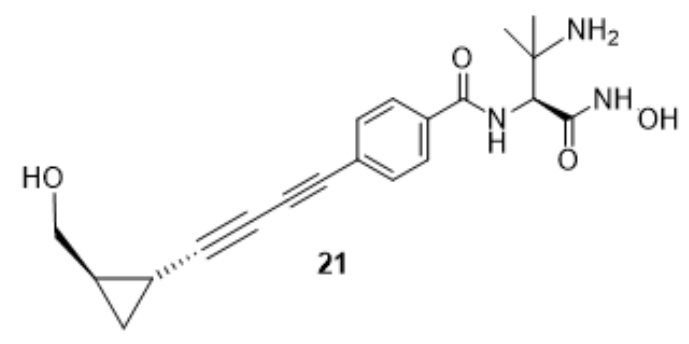

MIC $P$. aeruginosa ATCC $27853=0.25 \mu \mathrm{g} / \mathrm{mL}$

MIC E. coli ATCC $25922=0.125 \mu \mathrm{g} / \mathrm{mL}$

$\mathrm{IC}_{50} \mathrm{PA01}=0.05 \mathrm{nM}$

$\mathrm{IC}_{90} \mathrm{PA} 01=0.06 \mathrm{nM}$

$\mathrm{IC}_{90} E$. coli $=0.06 \mathrm{nM}$

Figure 7 


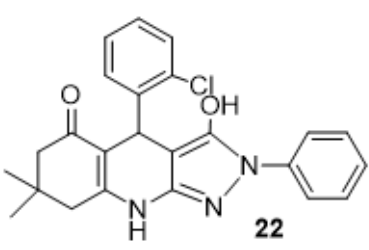

$\mathrm{IC}_{50} E$. coli $\Delta$ tolc $=32 \mu \mathrm{M}$ MIC $E$. coli $\Delta$ tolc $=3.13 \mu \mathrm{g} / \mathrm{mL}$

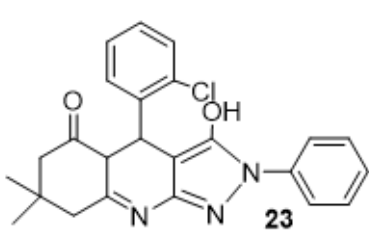

MTC $E$ coli $=128 \mu \mathrm{g} / \mathrm{mL}$

MIC $E$. coli $\Delta$ tolc $=1 \mu \mathrm{g} / \mathrm{mL}$ $\Delta$ tolc Plac::lpxD $=8 \mu \mathrm{g} / \mathrm{mL}$
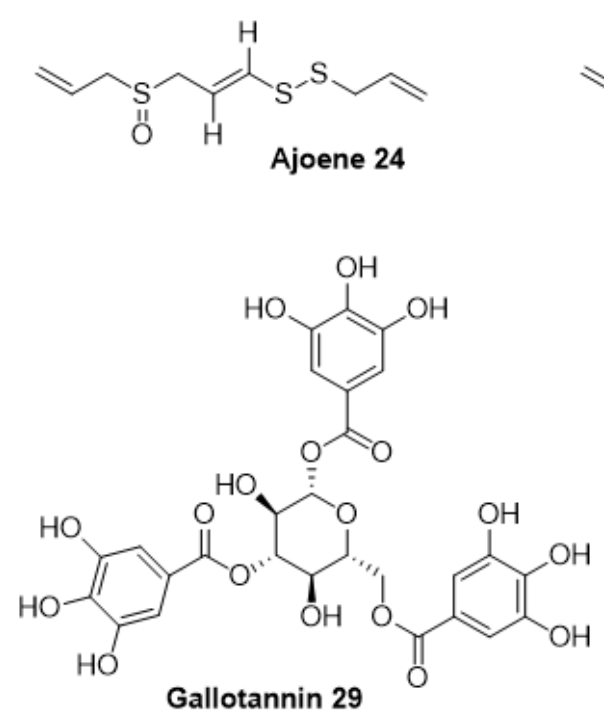
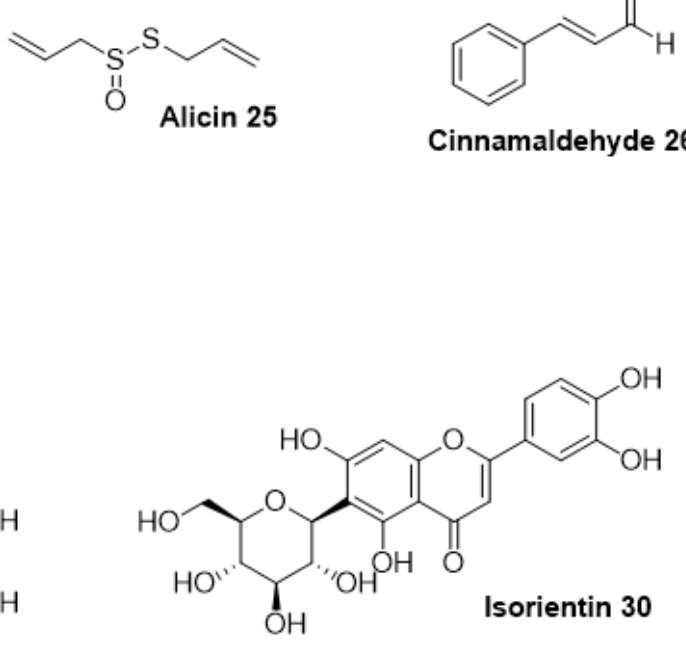

Cinnamaldehyde 26
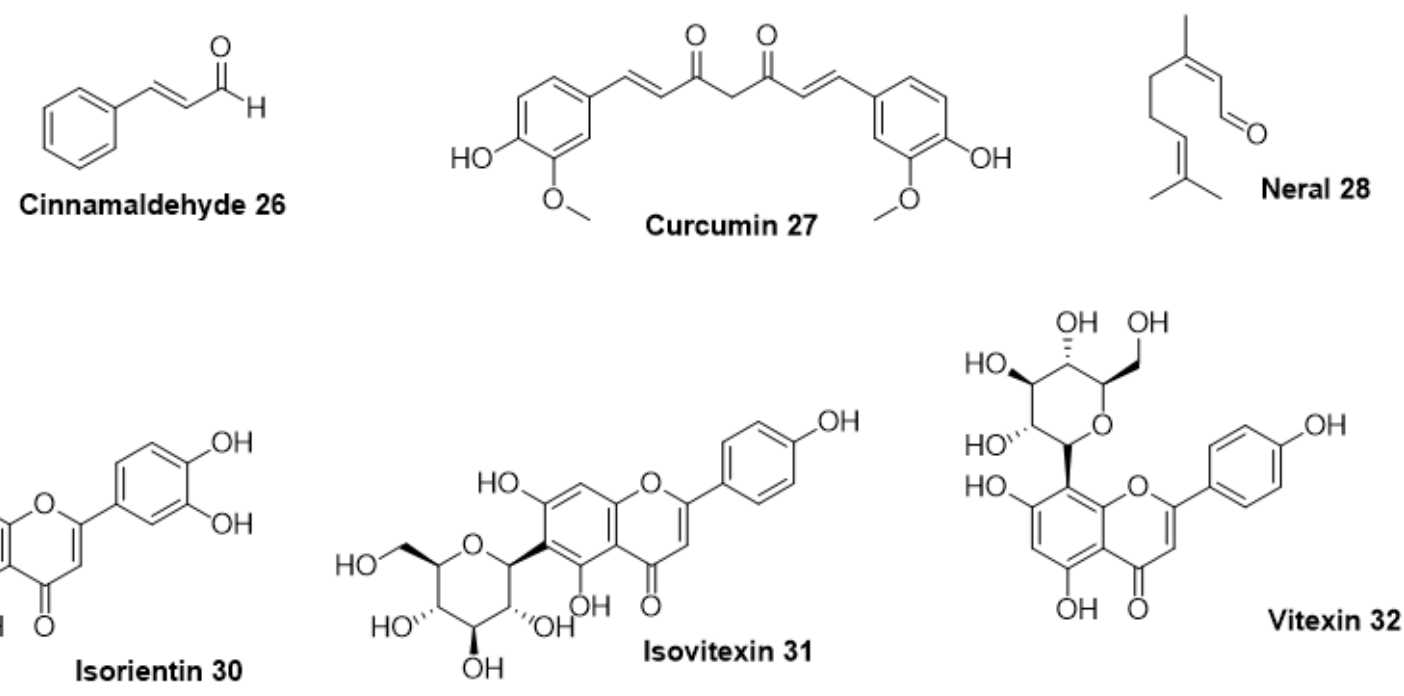
Figure 8

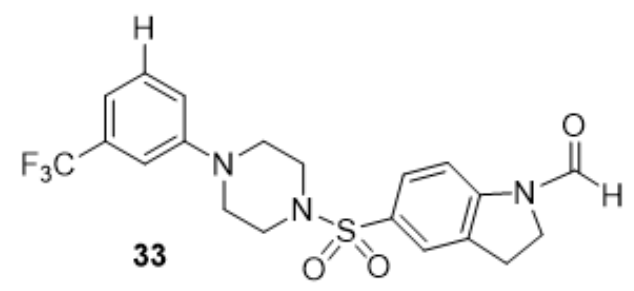

$\mathrm{IC}_{50}$ against $K$. pneumoniae $=0.36 \mu \mathrm{M}$

$\mathrm{IC}_{50}$ against $E$. coli $=0.14 \mu \mathrm{M}$

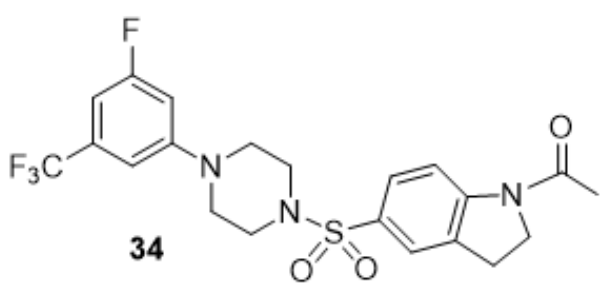

$\mathrm{IC}_{50}$ against $K$. pneumoniae $=0.11 \mu \mathrm{M}$

$\mathrm{IC}_{50}$ against $E$. coli $=0.083 \mu \mathrm{M}$

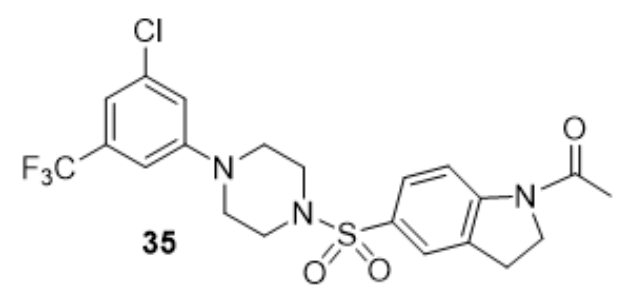

$\mathrm{IC}_{50}$ against $K$. pneumoniae $=0.026 \mu \mathrm{M}$ $\mathrm{IC}_{50}$ against $E$. coli $=0.046 \mu \mathrm{M}$

MIC against $K$. pneumoniae, E. coli ATCC 25922 and PA01 $=>64 \mu \mathrm{g} / \mathrm{mL}$

MIC against $K$. pneumoniae $=2.8 \mu \mathrm{g} / \mathrm{mL}$<smiles>O=C(CCCCNC(=O)Nc1ccc(S(=O)(=O)N2CCN(c3cc(Cl)cc(C(F)(F)F)c3)CC2)cc1)NO</smiles>

MIC against $K$. pneumoniae $=32 \mu \mathrm{g} / \mathrm{mL}$

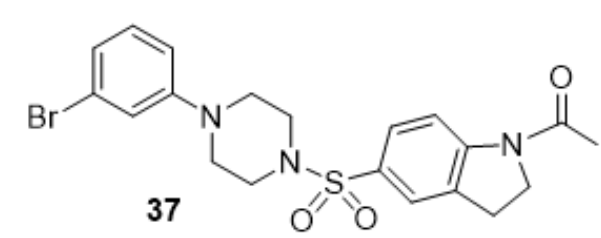

MIC against $K$. pneumoniae $=$ ND

\section{Figure 9}




\section{Target}

OM

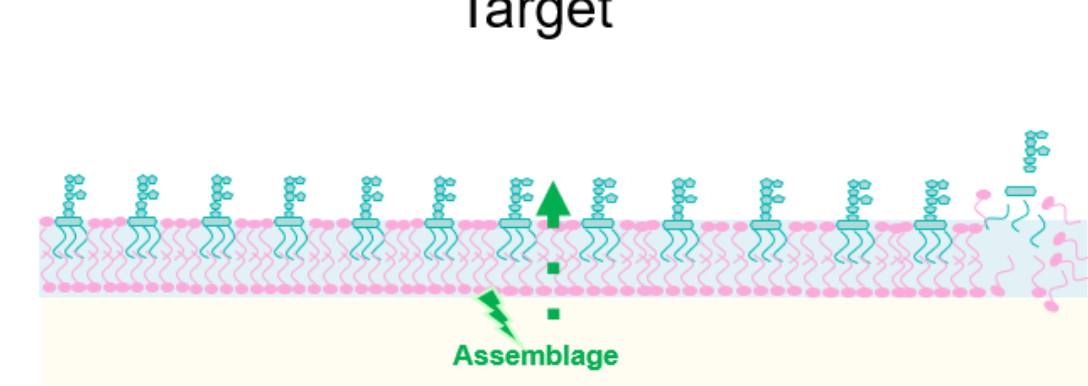

\section{Periplasm}
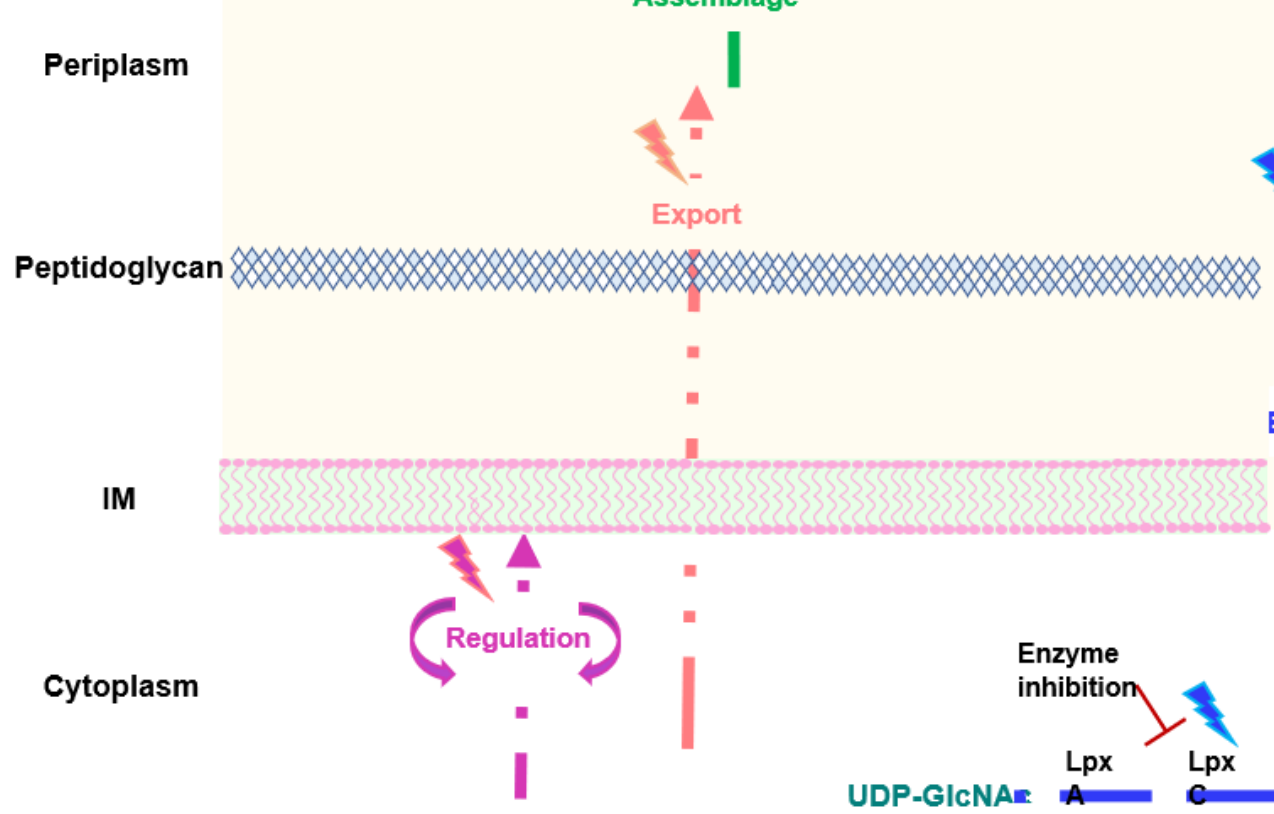

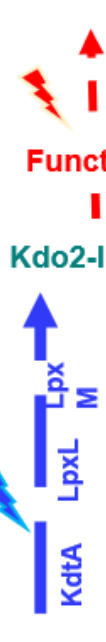
Kdo2-lipid A

x Biosynthesis

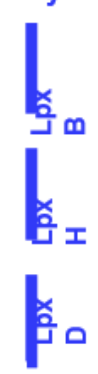

Target inhibition

- Function alteration

Abortive assemblage

Export defect

Block in biosynthesis

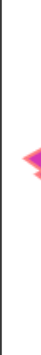

Regulation alteration

\section{Possible resistance}

* Functional shift

* Assemblage mutation
Bypass the export defect

Modification in biosynthesis pathway

Corrective mutation ( other mutation )

Impermeability, Efflux Bacterial enzymes

Figure 10 
Table of Contents graphic

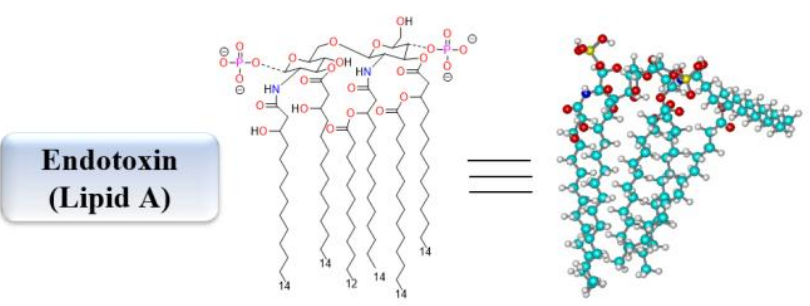

